Article

\title{
Assessing the Spatiotemporal Evolution of Anthropogenic Impacts on Remotely Sensed Vegetation Dynamics in Xinjiang, China
}

\author{
Jingyun Guan 1,2,3, Junqiang Yao ${ }^{4}$, Moyan Li ${ }^{1,2}$ and Jianghua Zheng ${ }^{1,2,5, *}$ \\ 1 College of Resources \& Environment Science, Xinjiang University, Urumqi 830046, China; \\ 107556519104@stu.xju.edu.cn (J.G.); 107556519105@stu.xju.edu.cn (M.L.) \\ 2 MOE Key Laboratory of Oasis Ecology, Xinjiang University, Urumqi 830046, China \\ 3 College of Tourism, Xinjiang University of Finance \& Economics, Urumqi 830012, China \\ 4 Institute of Desert Meteorology, China Meteorological Administration, Urumqi 830002, China; yaojq@idm.cn \\ 5 Institute of Arid Ecology and Environment, Xinjiang University, Urumqi 830046, China \\ * Correspondence: zheng.jianghua@xju.edu.cn; Tel.: +86-13579880590
}

Citation: Guan, J.; Yao, J.; Li, M.; Zheng, J. Assessing the Spatiotemporal Evolution of Anthropogenic Impacts on Remotely Sensed Vegetation Dynamics in Xinjiang, China. Remote Sens. 2021, 13, 4651. https://doi.org/10.3390/ rs13224651

Academic Editor: Brigitte Leblon

Received: 26 September 2021

Accepted: 10 November 2021

Published: 18 November 2021

Publisher's Note: MDPI stays neutral with regard to jurisdictional claims in published maps and institutional affiliations.

Copyright: (c) 2021 by the authors. Licensee MDPI, Basel, Switzerland. This article is an open access article distributed under the terms and conditions of the Creative Commons Attribution (CC BY) license (https:/ / creativecommons.org/licenses/by/ $4.0 /)$.
Abstract: The dynamics of the ecosystem represented by vegetation under the influence of human activities have become an important issue in the study of the regional ecological environment. Xinjiang is one of the most ecologically fragile areas in the world, and vegetation changes have received extensive attention. Xinjiang is one of the most ecologically fragile areas in the world, and vegetation changes have received extensive attention. However, the spatiotemporal patterns and evolutionary trends of anthropogenic impacts on vegetation dynamics in Xinjiang are still unclear. In this study, the anthropogenic impacts on vegetation dynamics were quantitatively assessed by combining the improved normalized difference vegetation index (NDVI) prediction model and the residual analysis method in Xinjiang, China. The human driving factors were analyzed with the support of a stepwise multiple regression model for vegetation changes at the county scale. Based on trend analysis and the Hurst exponent, the spatiotemporal characteristics and evolutionary trends of the impact of human activities on vegetation change were discussed. The results show that (1) the NDVI values in Xinjiang showed a gradually increasing trend at a rate of $0.005 / 10$ years from 1982 to 2018, and the vegetation dynamics mainly showed significant improvements (57.09\% of the vegetated areas), especially for crops. (2) The anthropogenic effects of vegetation changes in Xinjiang mainly included positive impact increases (43.22\% of the vegetated areas) from 2000 to 2018 . Human activities promoted the increase in the NDVI of various vegetation types. Both the positive and negative impacts of human activities increased over the study period, and the growth rate of the positive influence $(0.08 \% / 10$ years) was higher than that of the negative influence $(0.04 \% / 10$ years). (3) The cultivated area, GDP of primary industry, and population are the main anthropogenic factors causing the increase in NDVI, which dominate the vegetation greening in 30.34\%, 29.22\%, and 28.09\% of the counties in Xinjiang, respectively. The animal husbandry population, agricultural population, and livestock number are the main anthropogenic factors causing the decrease in NDVI, which dominate the vegetation degradation in $23.60 \%, 21.35 \%$, and $17.98 \%$ of the counties in Xinjiang, respectively. (4) The evolutionary trend of the anthropogenic impact on vegetation dynamics in Xinjiang will be dominated by anti-persistence (53.84\% of the vegetated areas), thereby mainly showing that the positive impacts continued to increase (22.56\% of the vegetated areas), especially for crops, shrubs, grasslands, and alpine vegetation. Our results are helpful in understanding the characteristics and evolutionary trends of vegetation changes in arid areas caused by human activities and are of significance as a reference for policymakers to appropriately adjust policy guidance in a timely manner to promote the protection and sustainable development of fragile ecosystems.

Keywords: vegetation dynamics; normalized difference vegetation index; anthropogenic impact; spatiotemporal pattern; evolutionary trend 


\section{Introduction}

As a critical component of terrestrial ecosystems, vegetation plays an indispensable role not only in the global carbon, nitrogen, oxygen, and water biogeochemical cycles [1-3], but also in ecosystem services, including reductions in greenhouse gases, the maintenance of climate stability [4-6], and the prevention of desertification [7]. Vegetation is commonly considered as a comprehensive indicator of ecological environmental changes [8], and its dynamics significantly affect regional ecological security [2,9]. In recent decades, as human activities have increased, changes in vegetation have profoundly recorded the imprints of human activities. Existing studies have found that anthropogenic activities change land use through urbanization, agricultural planting, grazing, and ecological restoration projects, thereby affecting the dynamic patterns of vegetation [10-12]. In the short term, the effects of anthropogenic activities on vegetation changes exceed those of natural factors in terms of the speed and extent of the vegetation changes [13]. In some ecologically fragile areas, anthropogenic activities have played an especially critical role in changing vegetation $[14,15]$. Therefore, understanding the impact of anthropogenic activities on vegetation has become essential for sustainable development $[11,16]$.

The normalized difference vegetation index (NDVI) is regarded as a valid indicator used for the monitoring of vegetation dynamics and environmental changes and has been widely used for the dynamic evaluation of vegetation at different scales $[10,17,18]$. Using NDVI data, previous studies have focused on the relationship between vegetation dynamics and human activities at a variety of spatiotemporal scales. For example, Ma et al. [19] studied the quantitative contribution of climate change and human activities to vegetation change in the Upper White Nile River and believed that the large proportion of agriculture, rapid population growth, and rapid urbanization were the main anthropogenic driving forces for vegetation change from 1982 to 2020. Liu and Xin [20] analyzed the impact of climate change and human activities on the changes in desert vegetation in China. The results show that human activities, especially the expansion of oases and sand control measures, were the two main reasons for the large increase in the green area of deserts in China from 2000 to 2017. Liu et al. [15] analyzed the impact of climate change and human activities from 1982 to 2015 on vegetation changes in the farming-pastoral ecotone in northern China and showed that anthropogenic contributions dominate trends of vegetation cover change in this area. These studies have improved our understanding of vegetation changes and their driving factors, but a more comprehensive and clearer picture for quantifying anthropogenic contributions to vegetation dynamics is still very necessary.

Currently, residual analysis is considered to be the most commonly used and most effective method to separate the relative influence of human and natural factors on vegetation [21]. The previous NDVI prediction models, dominated by natural factors, generally take temperature and precipitation as the primary indicators and lack consideration of other natural factors, such as solar radiation and soil moisture $[13,19,20,22,23]$. However, studies have confirmed that soil moisture and vegetation change cycles in arid areas have similar changing trends [24]. Soil moisture is the main driving factor of drought pressure in more than $70 \%$ of global vegetated areas, especially in semi-arid ecosystems [25]. Solar radiation not only affects the surface energy budgets and temperature but also the soil moisture balances, which is regarded as one of the most basic variables of the vegetation environment $[15,26]$. Merely considering temperature and precipitation is not sufficient to represent the state of vegetation change dominated by natural factors. Therefore, it is most important to accurately quantify the contribution of natural factors to the actual NDVI in the residual analysis method, because this process subsequently determines the level of anthropogenic contribution [21]. In addition, existing studies mostly analyzed human activities as a whole $[15,19,20]$, and lacked analysis of the contribution of different types of human activities to vegetation change. The contribution of different types of human activities to vegetation dynamics varies from place to place $[10,27,28]$. For instance, urbanization has led to the degradation of vegetation in most urban centers and surrounding areas in central and eastern China [10]. In the Pearl River Delta of China, economic growth 
(population and GDP) and vegetation cover have achieved a win-win situation [29], while in the eastern part of the Loess Plateau, GDP dominates the degradation of NDVI [28]. The expansion of cultivated land has promoted the greening of vegetation in Xinjiang [30]. The population and the number of livestock are the main human factors affecting the vegetation dynamics in Mongolia [27]. Therefore, it is essential for regional ecological protection to systematically analyze the contribution of different human activities to vegetation dynamics. Moreover, there are still a few results that specifically focus on the spatiotemporal patterns and evolutionary trends of anthropogenic impacts on vegetation changes.

Xinjiang is an extremely vulnerable region, with widespread deserts, frequent environmental challenges, and severe water scarcity [31-33]. Climate change effects have resulted in Xinjiang experiencing a change in climate after 1987 from a warm-dry climate to a warmwet climate [34,35]. Simultaneously, population growth, social development [36,37], and the implementation of a large number of ecological restoration policies, including the ThreeNorth Shelterbelt Forest Project (TNSP), Grain for Green Program (GGP), Comprehensive Control Project in Tarim River Basin (CCPT), and the Ten Forests Project in Xinjiang (TFP), has resulted in considerable changes to the ecological environment of the region, especially after 2000 [16,18,31,38]. However, few studies have been conducted to analyze how these factors affect vegetation variances in Xinjiang, especially for different anthropogenic factors. What are the spatiotemporal variation laws of anthropogenic impacts on vegetation dynamics in Xinjiang? What is the relative importance of different types of human activities to vegetation change in Xinjiang? What is the evolutionary trend of anthropogenic impacts on vegetation dynamics? The above questions do not yet have clear answers.

In this context, this study focused on the effects of anthropogenic activities on vegetation dynamics and aimed to solve the following problems: (1) Examine the spatial patterns and dynamic trends of vegetation in Xinjiang; (2) improve the NDVI prediction model dominated by natural factors, and quantitatively calculate the anthropogenic impacts on vegetation dynamics in Xinjiang; (3) analyze the relative importance of different types of human activities to vegetation changes; and (4) explore the spatiotemporal patterns and future evolutionary trends of anthropogenic influences on vegetation dynamics in Xinjiang. By understanding the characteristics and patterns of the anthropogenic influence on vegetation changes, decision-making support can be provided for the protection and sustainable development of fragile ecosystems in this area.

\section{Materials and Methods}

\subsection{Study Area}

Xinjiang $\left(73.66^{\circ}-96.38^{\circ} \mathrm{E}, 34.42^{\circ}-49.17^{\circ} \mathrm{N}\right)$ is located in the hinterland of the Eurasian continent, northwestern China (Figure 1a). It covers an area of more than 1.66 million $\mathrm{km}^{2}$, accounting for $1 / 6$ th of China's land area. Xinjiang has a complex topography. The Altai Mountains, Tianshan Mountains, and the Kunlun Mountains surround the Junggar Basin and the Tarim Basin, forming a unique mountain-oasis-desert landscape [39]. The Tianshan Mountains traverse the central part of Xinjiang and divide Xinjiang into two parts: Northern Xinjiang and Southern Xinjiang. Far away from the ocean, Xinjiang has a typical temperate continental arid and semi-arid climate. The annual precipitation is $145 \mathrm{~mm}$, which is only $23 \%$ of the national average precipitation, and there is an abnormal shortage of water resources [32,33]. Affected by topography and atmospheric circulation, precipitation in Xinjiang is unevenly distributed. The annual precipitation can reach more than $400 \mathrm{~mm}$ in the Yili River Basin, 100-200 mm in the north, and only 16-85 mm in the south [40]. Natural vegetation is sparse, mainly comprising grassland and sparse vegetation (Figure 1b), and the coverage is generally less than $20 \%$ [32]. In recent years, economic development, population growth, accelerated urbanization, and large-scale ecological restoration projects have had a significant impact on the local ecosystem. 

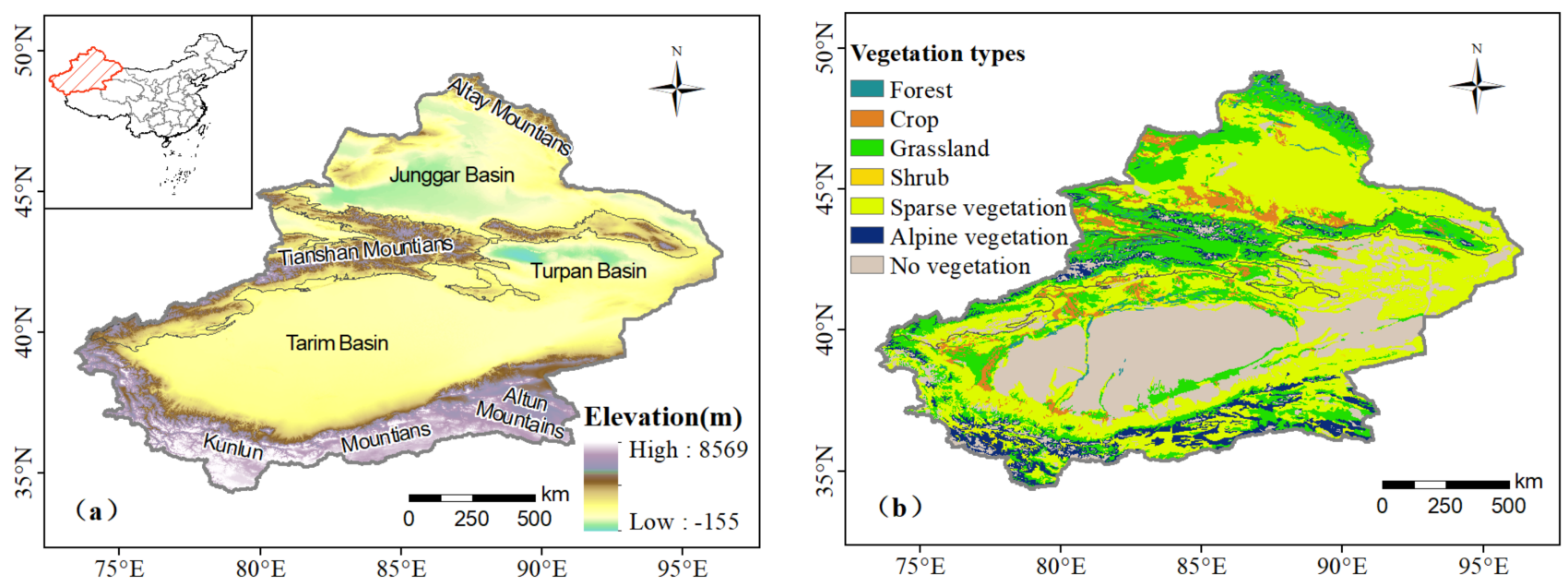

Figure 1. Study area. (a) Elevation; (b) vegetation types.

\subsection{Data Sources and Pre-Processing}

The datasets used in this study comprised NDVI, gridded temperature, precipitation, solar radiation, specific humidity, soil moisture, vegetation type, digital elevation model (DEM), land use data, and socio-economic statistics data (GDP of primary industry, population, agricultural population, animal husbandry population, cultivated areas, and livestock number). A summary of the data used in this study is listed in Table 1.

Table 1. Summary of the data sources used in this study.

\begin{tabular}{|c|c|c|c|c|}
\hline Dataset & $\begin{array}{l}\text { Time/Space } \\
\text { Resolution }\end{array}$ & Period & Data Sources & Purpose \\
\hline \multirow{2}{*}{ NDVI } & $15 \mathrm{~d} / 1 / 12^{\circ}$ & 1982-2015 & $\begin{array}{l}\text { Global Inventory Modeling and } \\
\text { Mapping Studies (GIMMS) } \\
\text { (https:/ / ecocast.arc.nasa.gov/, } \\
\text { accessed on } 1 \text { November 2019) }\end{array}$ & \multirow{2}{*}{$\begin{array}{c}\text { Geographical detector modeling } \\
\text { and residual analysis. }\end{array}$} \\
\hline & month $/ 0.05^{\circ}$ & 2000-2018 & $\begin{array}{l}\text { Moderate Resolution Imaging } \\
\text { Spectroradiometer (MODIS) } \\
\text { (https:/ / lpdaac.usgs.gov/, } \\
\text { accessed on } 5 \text { January 2020) }\end{array}$ & \\
\hline Meteorological & $3 \mathrm{~h} / 0.1^{\circ}$ & 1982-2018 & $\begin{array}{l}\text { Meteorological Forcing Dataset } \\
\text { (CMFD) (http:/ / data.tpdc.ac.cn, } \\
\text { accessed on } 15 \text { January 2020) }\end{array}$ & \multirow{3}{*}{$\begin{array}{c}\text { Geographical detector modeling } \\
\text { and NDVI prediction based on } \\
\text { natural factors. }\end{array}$} \\
\hline \multirow{2}{*}{ Soil moisture } & month $/ 0.25^{\circ}$ & 1982-2010 & $\begin{array}{l}\text { Global Land Data Assimilation } \\
\text { System (GLDAS-2.0) } \\
\text { (https:/ / disc.gsfc.nasa.gov/, } \\
\text { accessed on } 15 \text { March 2020) }\end{array}$ & \\
\hline & month $/ 0.25^{\circ}$ & 2000-2018 & $\begin{array}{l}\text { Global Land Data Assimilation } \\
\text { System (GLDAS-2.1) } \\
\text { (https:/ / disc.gsfc.nasa.gov/, } \\
\text { accessed on } 15 \text { March 2020) }\end{array}$ & \\
\hline Vegetation type & $1 \mathrm{~km}$ & 2001 & \multirow{3}{*}{$\begin{array}{l}\text { Resource and Environment Data } \\
\text { Cloud Platform } \\
\text { (http:/ / www.resdc.cn/, } \\
\text { accessed on } 10 \text { April 2020) }\end{array}$} & $\begin{array}{l}\text { Regional division of different } \\
\text { types of vegetation. }\end{array}$ \\
\hline DEM & $90 \mathrm{~m}$ & & & $\begin{array}{l}\text { Calculate elevation, aspect, and } \\
\text { slope. }\end{array}$ \\
\hline Land use data & $1 \mathrm{~km}$ & 2000 and 2018 & & Analyze land-use changes. \\
\hline $\begin{array}{l}\text { Socio-economic } \\
\text { statistics data }\end{array}$ & county & 2000-2018 & $\begin{array}{l}\text { Xinjiang Statistical Yearbook } \\
\text { 2001-2019. }\end{array}$ & $\begin{array}{c}\text { Analyze the relative contribution } \\
\text { of human activities. }\end{array}$ \\
\hline
\end{tabular}




\subsubsection{NDVI Dataset}

The NDVI data of the Global Inventory Modeling and Mapping Studies (GIMMS) group covering the period from 1982 to 2015 were sourced from the NASA Ames Ecological Forecasting Lab (https: / / ecocast.arc.nasa.gov/, (accessed on 1 November 2019)) with spatial and temporal resolutions of $1 / 12^{\circ}$ and $15 \mathrm{~d}$, respectively. The monthly GIMMS NDVI data were preprocessed using the maximum value composite method to minimize the impact of scattering by the atmosphere and aerosols [41]. The NDVI data of the Moderate Resolution Imaging Spectroradiometer (MODIS) covering the period from 2000 to 2018 were obtained from the NASA Land Processes Distributed Active Archive Center (https: / / lpdaac.usgs.gov/, (accessed on 5 January 2020)) with spatial and temporal resolutions of $0.05^{\circ}$ and 1 month, respectively. Studies have shown a good linear relationship between the NDVI data of GIMMS and MODIS, thereby indicating that MODIS NDVI data can be linearly corrected [14]. Using data from the overlapping period of 2000-2015, we established a per-pixel unary linear regression model [42,43]. The relationship expression was then used to estimate and extend the time series of the GIMMS NDVI data. The specific steps were as follows: first, the resolution of the MODIS NDVI data was resampled from $0.05^{\circ}$ to $1 / 12^{\circ}$ by means of the bilinear interpolation method, in order to match the resolution of the monthly GIMMS NDVI data [44]. A unary linear regression model was then established using the overlapping time between the GIMMS NDVI data and the resampled MODIS NDVI data (2000-2015). Linear regression was then used to extend the monthly GIMMS NDVI data from 2016 to 2018. The growing season was defined as from April to October each year, and the average value of the NDVI in each month of the growth season represents the vegetation coverage state of that year.

\subsubsection{Meteorological Dataset}

The gridded temperature, precipitation, specific humidity, and solar radiation data were collected from the China Meteorological Forcing Dataset (CMFD) at the National Tibetan Plateau Data Center (http:/ / data.tpdc.ac.cn, (accessed on 15 January 2020)). The CMFD provided data for the period of 1982-2018 with spatial and temporal resolutions of $0.1^{\circ}$ and $3 \mathrm{~h}$, respectively $[45,46]$. The CMFD has been widely applied in many research fields, such as for the validation of climate models, modeling of the land surface, scheduling of crop planting, and assimilation of land data, due to its long length and high stability and continuity $[38,47]$. To be consistent with the NDVI data, bilinear interpolation was used to resample the meteorological data to $1 / 12^{\circ}$ [44].

\subsubsection{Soil Moisture Dataset}

The soil moisture data were obtained from the Global Land Data Assimilation System (GLDAS; https:// disc.gsfc.nasa.gov/, (accessed on 15 March 2020)) and consisted of four soil depths: 0-10 cm, 10-40 cm, 40-100 cm, and 100-200 cm. Based on data available from multiple sources, many past studies $[48,49]$ have validated GLDAS soil moisture datasets. In this research, we used GLDAS-2.0 data (NOAH Model; $0.25^{\circ} \times 0.25^{\circ}$ ) for the period of 1982-2010 and GLDAS-2.1 data (NOAH Model; $0.25^{\circ} \times 0.25^{\circ}$ ) for the period of 2000-2018. Using overlapping data from 2000 to 2010, the GLDAS-2.0 soil moisture data were estimated and extended according to the same data processing method used for the NDVI data to maintain the consistency of the data series [42]. Similarly, to be consistent with the NDVI data, the soil moisture data were resampled to $1 / 12^{\circ}$ using bilinear interpolation [44].

\subsubsection{Other Data}

This research also used DEM, vegetation type, and land use type data obtained from the Resource and Environment Data Cloud Platform (http:/ /www.resdc.cn/, (accessed on 10 April 2020)). Among them, DEM data with a spatial resolution of $90 \mathrm{~m}$ were used to calculate the elevation, aspect, and slope in the study area. The 1:1,000,000 vegetation type data of China published in 2001 were divided into eleven vegetation types with 
a spatial resolution of $1 \mathrm{~km}$. The original eleven vegetation types were merged into seven categories: crops (cultivated vegetation), forests (broadleaved forests, coniferous forests, and mixed forests), shrubs, grasslands (steppes, meadows, grasslands, wetlands) [40], alpine vegetation, sparse vegetation, and no vegetation (Figure 1b). The 2000 and 2018 land use data with resolutions of $1 \mathrm{~km}$ were used for the land use type transfer analysis. The land-use types include 6 types of cultivated land, forest land, grassland, water area, built-up land, and unused land (bare soil). To match the remote sensing data, the spatial resolution of the above data was resampled to $1 / 12^{\circ}$. For the DEM, this was conducted using bilinear interpolation, and for vegetation type and land use type, this was conducted using the nearest-neighbor approach [44]. The socio-economic statistics data at the county level from 2000 to 2018 were obtained from the Xinjiang Statistical Yearbook 2001-2019. All of the livestock data were transformed into sheep units in accordance with the "Calculation of proper carrying capacity of rangelands" (NY/T 635-2002) issued by the Ministry of Agriculture of the People's Republic of China.

\subsection{Methods}

Figure 2 shows an overview of the general technical flowchart followed in this study. It mainly includes five steps. (1) Screen the main natural factors that affect vegetation changes through geographic detectors. (2) Improve the NDVI prediction model dominated by natural factors, and calculate the predicted NDVI. (3) Use residual analysis to separate the influence of natural factors and human activities on the changes in NDVI. (4) Analyze the relative contribution of different types of human activities to vegetation changes based on a stepwise multiple regression model. (5) Employ the Hurst exponent to explore the evolutionary trend of human influence on vegetation dynamics.

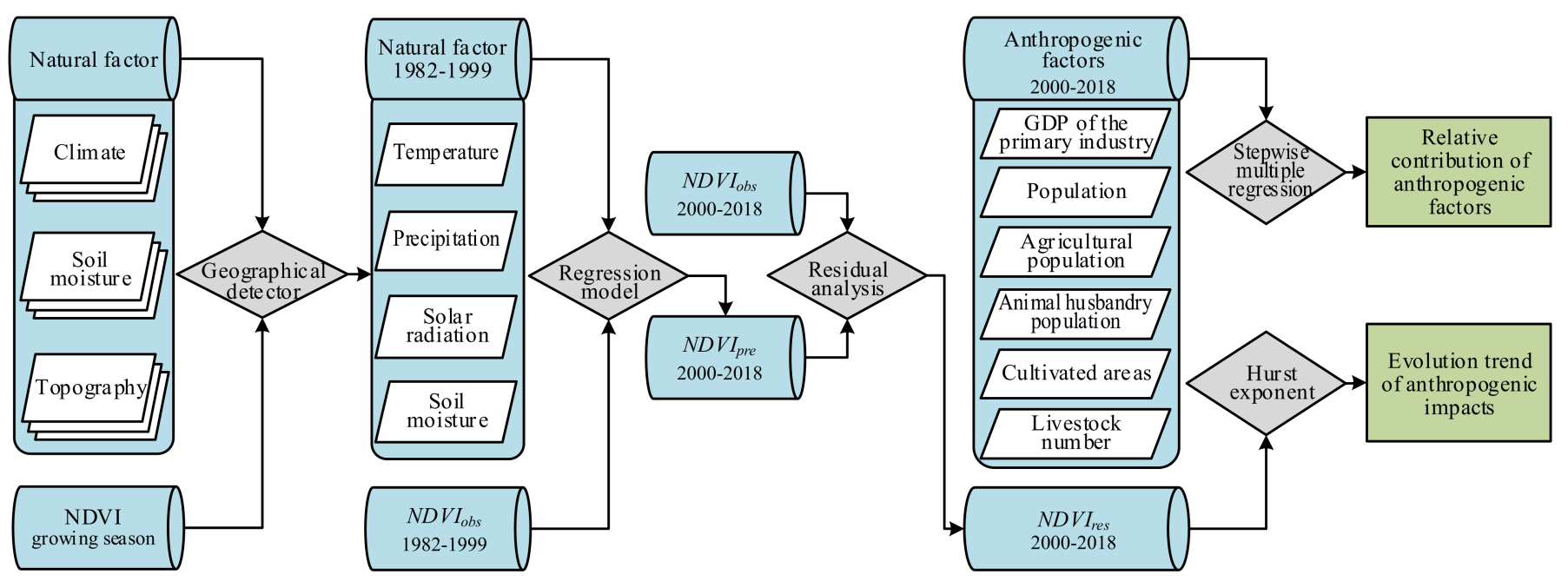

Figure 2. Technical flowchart of the impact assessment of human factors on vegetation dynamics. $N D V I_{\text {obs }}, N D V I_{\text {pre }}$, and $N D V I_{\text {res }}$ represent observed NDVI, predicted NDVI based on natural factors, and NDVI affected by human activities, respectively.

\subsubsection{Geographical Detector Method}

The geographic detector is a new set of spatial statistical methods that detect spatial differentiation and reveal the driving forces behind them [50]. To solve different scientific problems, four kinds of geographic detectors are proposed, namely factor, interaction, risk, and ecological detectors. Among them, the factor detector can reveal to what extent a certain factor explains the spatial differentiation of a geographical feature [50-52]. In this study, we use the factor detector to detect the relative contribution of different natural factors to the spatial differentiation of NDVI in Xinjiang. The main steps are as follows.

(1) Index selection and grading: previous studies have shown that natural factors such as temperature, precipitation [22,32], solar radiation [15], soil moisture [4,53], and 
terrain [52] are considered to have important impacts on vegetation. Eleven indicators were systematically selected based on the principles of representativity, scientific rigor, quantifiability, and availability, to detect the influence of natural factors on changes to the NDVI in Xinjiang (Table 2). Using the natural breakpoint method [52,54], the average annual precipitation, average annual temperature, solar radiation, specific humidity, soil moisture, and elevation were divided into six classes, whereas the slope and aspect dimensions were divided into nine and ten categories, respectively.

(2) Information extraction: According to the area of Xinjiang, 16,600 random sampling point files were generated in GIS software based on $10 \mathrm{~km} \times 10 \mathrm{~km}$ grids [52]. According to the spatial location, the vegetation NDVI and natural factor grading data of the sampling points were then correlated to generate a property sheet. Finally, the quantitative relationship between the corresponding NDVI value and each index was obtained.

(3) Geographical detector model: The factor detection module can be used to detect the interpretation degree of the spatial differentiation of property $\mathrm{Y}$ by factor $\mathrm{X}$. The degree of spatial association between the natural factor $(X)$ and the NDVI $(Y)$ can be measured by the q-statistic. The calculation of the q-statistic was completed using geographic detector model software (http:/ /www.geodetector.cn/, accessed on 20 April 2020). The model formula is as follows:

$$
q=1-\frac{\sum_{h=1}^{L} N_{h} \sigma_{h}^{2}}{N \sigma^{2}}
$$

where $q$ represents the explanatory power of a natural factor on the NDVI value of vegetation with a value range of $[0,1]$, and the value of the natural factor is positively correlated with its power to predict the NDVI [51]; $h=1, \cdots$, L denotes the classification or partition of natural factor $\mathrm{X} ; \mathrm{N}$ and $\mathrm{Nh}$ are the samples of the study area and sub-region $\mathrm{h}$, respectively; and $\sigma_{h}^{2}$ and $\sigma^{2}$ represent the variances in the sub-region $\mathrm{h}$ and the $Y$ value of the study area (in this study, the NDVI), respectively.

Table 2. The natural factor index for the study area.

\begin{tabular}{ccccc}
\hline Type of Natural Factors & Code & Index & Unit & q Statistic \\
\hline Climate & X1 & Average annual temperature & ${ }^{\circ} \mathrm{C}$ & $0.3640^{* *}$ \\
& X2 & Average annual precipitation & $\mathrm{mm}$ & $0.5332^{* *}$ \\
& X3 & Solar radiation & $\mathrm{kw} / \mathrm{m}^{2}$ & $0.2471^{* *}$ \\
& X4 & Specific humidity & $\mathrm{g} / \mathrm{kg}$ & $0.0935^{* *}$ \\
Soil moisture & X5 & Soil moisture $(0-10 \mathrm{~cm})$ & $\mathrm{kg} / \mathrm{m}^{2}$ & $0.2677^{* *}$ \\
& X6 & Soil moisture $(10-40 \mathrm{~cm})$ & $\mathrm{kg} / \mathrm{m}^{2}$ & $0.0270^{* *}$ \\
& X7 & Soil moisture $(40-100 \mathrm{~cm})$ & $\mathrm{kg} / \mathrm{m}^{2}$ & $0.1969^{* *}$ \\
Topography & X8 & Soil moisture $(100-200 \mathrm{~cm})$ & $\mathrm{kg} / \mathrm{m}^{2}$ & $0.1251^{* *}$ \\
& X9 & Elevation & $\mathrm{m}$ & $0.1042^{* *}$ \\
& X10 & Slope & degree & $0.0233^{* *}$ \\
& X11 & Aspect & degree & $0.0018^{* *}$ \\
\hline
\end{tabular}

** Significance level was less than 0.01 .

Through the above steps, the q values of each natural factor were calculated to reveal the influence of the factor on the NDVI (Table 2). In this study, natural factors with explanatory powers greater than $20 \%$ were selected to establish the NDVI prediction model based on natural factors, including average annual precipitation, solar radiation, average annual temperature, and soil moisture $(0-10 \mathrm{~cm})$. 


\subsubsection{The Estimation of Sen's Slope}

Sen's slope method utilizes the median of a sequence to identify a trend, and this approach can, to a certain extent, eliminate the influence of data anomalies in trend tests and reduce noise interference [55]. The calculation formula is as follows:

$$
\beta=\operatorname{Median}\left(\frac{x_{j}-x_{i}}{j-i}\right), \forall j>i
$$

where $x_{i}$ and $x_{j}$ represent the data values $(j>i)$ at times $i$ and $j$, respectively. The trend degree $\beta$ is used to judge the rise and fall of the time series trend. When $\beta>0$, the time series shows an upward trend; otherwise, it shows a downward trend.

\subsubsection{Mann-Kendall Significance Test}

The Mann-Kendall (M-K) significance test $[56,57]$ is generally combined with Sen's slope method to complete the significance test of sequence trends $[13,22,58]$. The formulas are as follows:

$$
\begin{gathered}
Z= \begin{cases}\frac{S-1}{\sqrt{\operatorname{var}(S)}} & S>0 \\
0 & S=0 \\
\frac{S+1}{\sqrt{\operatorname{var}(S)}} & S<0\end{cases} \\
S=\sum_{i=1}^{n-1} \sum_{i=1}^{n} \operatorname{sgn}\left(x_{j}-x_{i}\right) \\
\operatorname{var}(S)=\frac{n(n-1)(2 n+5)}{18} \\
\operatorname{sgn}\left(x_{j}-x_{i}\right)=\left\{\begin{array}{rr}
1 & x_{j}-x_{i}>0 \\
0 & x_{j}-x_{i}=0 \\
-1 & x_{j}-x_{i}<0
\end{array}\right.
\end{gathered}
$$

where $n$ represents the length of the time series, $x_{j}$ and $x_{i}$ are the data values at times $j$ and $i$ $(j>\mathrm{i})$, respectively, and $\operatorname{sgn}\left(x_{j}-x_{i}\right)$ is the symbolic function. Under a set significance level $\alpha,|Z|>u_{1-\alpha / 2}$ represents a significant change in the time series. When $|Z|$ is greater than $1.65,1.96$, and 2.58 , it means that the time series has passed the significance test at $90 \%, 95 \%$, and $99 \%$ probability, respectively.

\subsubsection{Residual Analysis}

The direct quantification of the impacts of anthropogenic activities on vegetation is difficult due to the lack of long-term serial observation data on the impacts of anthropogenic activities on the NDVI $[13,22]$. Residual analysis can separate NDVI changes caused by natural factors and NDVI changes caused by human activities and is widely used in the study of the impact of natural factors and human activities on vegetation changes [13,15,19-23]. The basic concept of residual analysis is as follows.

First, a regression model between the predicted NDVI (NDVI $\left.I_{\text {pre }}\right)$ and natural factors was established as follows:

$$
N D V I_{\text {pre }}=b_{0}+b_{1} N_{1}+b_{2} N_{2}+\cdots+b_{m} N_{m}
$$

where $N D V I_{\text {pre }}$ is the NDVI based on natural factors; $N_{1}, N_{2}, \ldots$, and $N_{m}$ are the natural factors that impact the NDVI; and $b_{0}, b_{1}, b_{2}, \ldots$, and $b_{\mathrm{m}}$ are the regression coefficients determined by the least square method.

Considering that large-scale ecological projects have been carried out in the study area since 2000, this research divided the entire research period into two phases: 1982-1999 and 2000-2018. During the 1982-1999 period, human activities had relatively little impact on vegetation changes, and so we used the observed NDVI $\left(N D V I_{o b s}\right)$ and natural factors during this period to calculate the regression coefficients $[15,31]$. Then, the $N D V I_{\text {pre }}$ values 
from 2000 to 2018 were calculated using the regression coefficients obtained from the 1982-1998 period.

Finally, the residuals between the $N D V I_{o b s}$ and $N D V I_{\text {pre }}$ were calculated and defined as the $N D V I_{\text {res }}$. The $N D V I_{\text {res }}$ represents the NDVI values that are influenced by anthropogenic activities. $N D V I_{\text {res }}>0$ indicates that vegetation increases under anthropogenic impacts, and $N D V I_{\text {res }}<0$ indicates that vegetation decreases under human impacts. The calculation formula is as follows.

$$
N D V I_{\text {res }}=N D V I_{o b s}-N D V I_{\text {pre }}
$$

The correlation coefficients of $N D V I_{o b s}$ and $N D V I_{\text {pre }}$ in areas without human influence were used to verify the regression model. First, the areas without human influence are extracted. Through many experiments and field observation experience, the areas where the absolute value of $N D V I_{\text {res }}$ change trend less than 0.0001 from 2000 to 2018 were extracted as the areas without human influence. By superimposing the land use type data, the extracted grid areas were judged one by one, and the areas that may be affected by human activities (such as built-up lands, cultivated lands) are eliminated, and the actual areas without human influence were finally obtained. Then, correlational analysis was conducted on $N D V I_{o b s}$ and $N D V I_{\text {pre }}$ in areas without human influence, and the accuracy of the regression model was judged by correlation coefficients.

\subsubsection{Stepwise Multiple Regression Model}

Population, agricultural planting, and grazing are the main anthropogenic driving forces that affect the dynamic vegetation pattern $[10,11,15]$. Xinjiang is one of the most important agricultural and pastoral areas in China. The irrigated area and the number of livestock are related to the development of the local agriculture and pastoral economy, and the population is undoubtedly the main participating factor in the economic development of agriculture and animal husbandry. Based on the availability of data and the collinearity between various factors (variance inflation factor is less than 10), we finally selected six indicators (GDP of primary industry, population, agricultural population, animal husbandry population, cultivated areas, and livestock number) as the driving factors of changes in $N D V I_{\text {res }}$.

A multiple stepwise regression model was used to determine the main human activity driving factors affecting $N D V I_{\text {res }}$ in Xinjiang. The ultimately determined regression and predictor variables are represented by Equation (9):

$$
N D V I_{\text {res }} \sim G D P 1+P o p+P o p 1+P o p 2+C A+L N
$$

where GDP1 represents the GDP of the primary industry; Pop, Pop 1 , and Pop 2 represent the population, agricultural population, and animal husbandry population, respectively; and $C A$ and $L N$ are cultivated areas and livestock number, respectively.

First, we calculated the average value of $N D V I_{\text {res }}$ according to the scope of each county, to match the $N D V I_{\text {res }}$ with each human activity factor according to the scope of the county. Then, based on the multiple regression framework, the relative importance of a single human activity factor to the change in $N D V I_{\text {res }}$ was determined. The LindemanMerenda-Gold (LMG) model can effectively avoid the order effect of regression variables and accurately quantify the contribution of single regression factors to multiple regression models, which has been widely used in relative importance analysis $[27,59,60]$. This study used the LMG model to measure the relative importance of different types of human activities to the vegetation changes in Xinjiang. The LMG model was bootstrapped using 1000 replicates, yielding a 95\% confidence interval. This method uses the R package "relaimpo" for calculations [59].

\subsubsection{Hurst Exponent}

The Hurst exponent [61] is widely used to evaluate the intensity of the persistence or anti-persistence of a change in the trend of a time series [22,23,32]. The Hurst exponent was 
used in this study to explore the future evolution of anthropogenic impacts on vegetation cover in Xinjiang. The main calculation steps for the time series of $N D V I_{t}(t=1,2,3, \ldots, n)$ are as follows:

$$
\begin{gathered}
\overline{\operatorname{NDVI}}_{(\tau)}=\frac{1}{\tau} \sum_{t=1}^{\tau} \operatorname{NDVI_{(\tau )}} \tau=1,2,3, \ldots, n \\
X_{(t, \tau)}=\sum_{j=1}^{\tau}\left(\operatorname{NDVI_{(j)}}-\overline{\operatorname{NDVI}}_{(\tau)}\right) 1 \leq t \leq \tau \\
R_{(\tau)}=\max _{1 \leq t \leq \tau} X_{(t, \tau)}-\min _{1 \leq t \leq \tau} X_{(t, \tau)} \tau=1,2,3, \ldots, n \\
S_{(\tau)}=\left[\frac{1}{\tau} \sum_{t=1}^{\tau}\left(N D V I_{(t)}-N D V I_{(\tau)}\right)^{2}\right]^{\frac{1}{2}} \tau=1,2,3, \ldots, n \\
\frac{R(\tau)}{S(\tau)}=(c \tau)^{H}
\end{gathered}
$$

where $H$ ranges from 0 to $1 . H>0.5$ indicates a persistent time series, thereby indicating that the $N D V I_{\text {res }}$ time series will present the same trend in the future as that in the past. $H=0.5$ indicates a random time series, thereby showing that the future $N D V I_{\text {res }}$ trend is independent of the trend occurring during the study period. $H<0.5$ indicates an antipersistent time series, thereby indicating that the future patterns of the changes in $N D V I_{\text {res }}$ will likely be opposite to those that occurred in the past.

\section{Results}

\subsection{Spatiotemporal Changes in the NDVI}

Judging from the spatial pattern of the average annual NDVI from 1982 to 2018 (Figure 3a), the NDVI of Xinjiang is generally high in the north and west and low in the south and east. The high-value areas of NDVI are mainly concentrated in the Altai Mountains, the central Tianshan Mountains, and the Yili River Valley, and the average NDVI value exceeds 0.5 . These areas are mainly dominated by forests and grasslands. The areas with an average NDVI of 0.3-0.5 mainly occur in the oasis in the northern part of Tianshan Mountains, Tacheng, and the northern and western parts of the Tarim Basin, and these areas are mainly dominated by croplands. Other areas controlled by grasslands have lower NDVI values, at between 0.2 and 0.3 , and are mainly in the Junggar Basin and northern foot of the Kunlun Mountains. The areas with the lowest NDVI values, at below 0.1 or even lower, are located in the southern Turpan Basin and the Taklimakan Desert, and are mainly composed of deserts.

The changing trend of the NDVI obtained based on Sen's slope method showed that the annual change rate of the NDVI in Xinjiang was between - 0.004/year and 0.013/year, and the average change rate was $0.005 / 10$ years, which means that the NDVI of Xinjiang presents an increasing trend from 1982 to 2018 (Figures 3b and 4). A combination of the results of the M-K test and those of Sen's slope analysis can reflect the trends of the NDVI variation more effectively. Based on the 0.05 confidence level, the results of the $\mathrm{M}-\mathrm{K}$ test could be divided into two categories: significant $(Z>1.96$ or $Z<-1.96)$ and insignificant $(-1.96 \leq Z \leq 1.96)$. The results of Sen's slope analysis and the $M-K$ test were superimposed according to Table 3 , and the results were divided into five types. Figure $3 \mathrm{c}$ demonstrates that the trend pattern of the NDVI series from 1982 to 2018 had obvious spatial heterogeneity, and the overall trend of vegetation in Xinjiang was gradually improving over this period; however, decreasing trends still existed in certain areas. Overall, 78.33\% of the vegetated area showed an improving trend, of which $57.09 \%$ showed a significantly increasing trend $(p<0.05)$. These regions were distributed mainly on the northern slope of the Tianshan Mountains, in oasis areas in the middle and upper reaches of the Tarim River, and at the northern foot of the Kunlun Mountain. Approximately $21.67 \%$ of the vegetated area showed decreasing trends, and the areas with significantly decreasing trends $(p<0.05)$ 
were mainly located in Junggar Basin, Turpan Basin, and northern Tarim Basin, accounting for $15.17 \%$ of the vegetated area (Figure $3 \mathrm{c}, \mathrm{d}$ ).
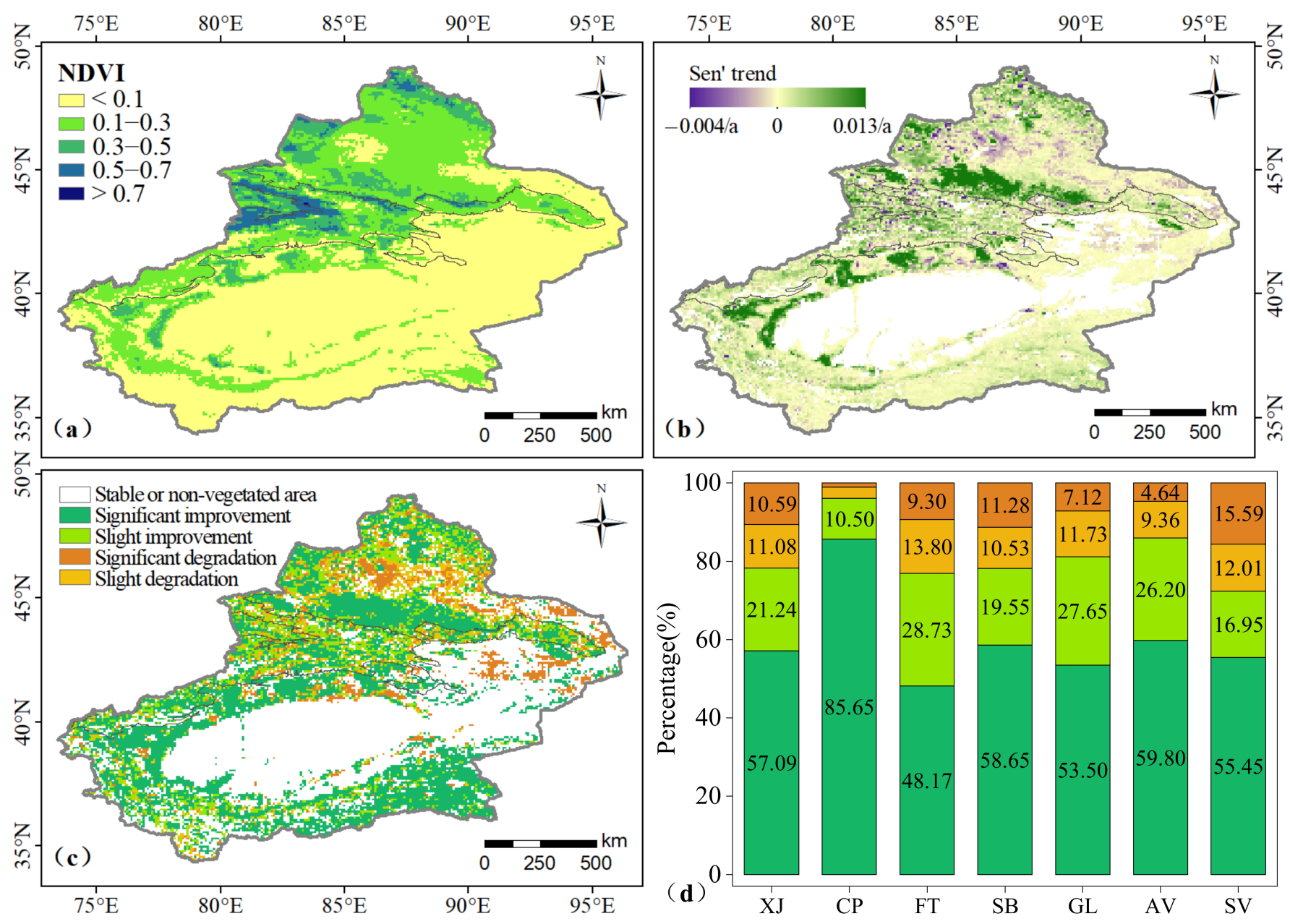

Figure 3. Changes in vegetation NDVI from 1982-2018. (a) Spatial patterns of average NDVI; (b) annual change trends; (c) types of change patterns and (d) percentage changes of NDVI for different vegetation types. The legend of (d) is the same as that of (c). XJ: Xinjiang; CP: crop; FT: forest; SB: shrub; GL: grassland; AV: alpine vegetation; SV: sparse vegetation.

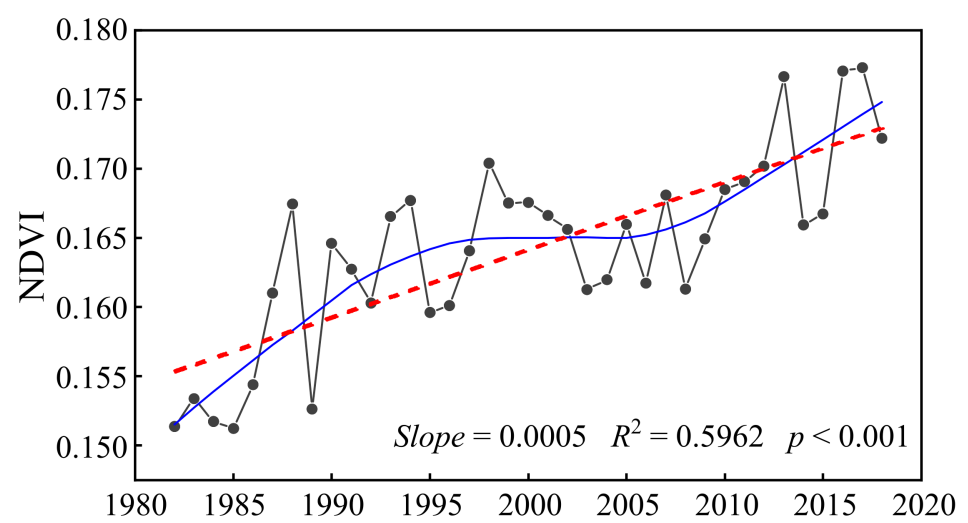

Figure 4. Interannual change of NDVI during the growing season in Xinjiang from 1982 to 2018. The linear trend (red dashed line) is based on Sen's trend estimation, and the nonlinear trend (blue solid line) is fitted with LOWESS. In the calculation of LOWESS, the smoother span is set as 0.5. 
Table 3. Division and statistics of the NDVI variation trend.

\begin{tabular}{ccc}
\hline$S_{N D V I}$ & $|\mathrm{Z}|$ & NDVI Trend \\
$\geq 0.0001$ & $>1.96$ & Significant improvement \\
$\geq 0.0001$ & $\leq 1.96$ & Slight improvement \\
$-0.0001-0.0001$ & $\leq 1.96$ & Stable or non-vegetated area \\
$\leq-0.0001$ & $\leq 1.96$ & Slight degradation \\
$\leq-0.0001$ & $>1.96$ & Significant degradation \\
\hline
\end{tabular}

In the last 37 years, the changes to all types of vegetation have shown an improvement trend (that is, NDVI showed an increasing trend), especially for crops, for which the area significantly improved, accounting for $85.65 \%$ (Figure 3d). For forests, $48.17 \%$ and $28.73 \%$ of the area showed significant and slight improvement trends, respectively, and the proportion of significant degradation was $9.30 \%$. The areas where shrubs, grasslands, alpine vegetation, and sparse vegetation were significantly improved accounted for $58.65 \%$, $53.50 \%, 59.80 \%$, and $55.45 \%$ of their respective areas, respectively. Significantly degraded (that is, NDVI showed a decreasing trend) areas accounted for $11.28 \%, 7.12 \%, 4.64 \%$, and $15.59 \%$ of their respective areas, respectively.

\subsection{Spatiotemporal Characteristics of Anthropogenic Impacts on Vegetation Dynamics}

Figure 5 a shows that the average $N D V I_{\text {res }}$ value in the study area was 0.0013 , and most areas $(54.99 \%)$ had positive $N D V I_{\text {res }}$ values; these areas were mainly distributed on the northern slope of the Tianshan Mountains and in the northwest region of the Tarim Basin. From the changing trends, the annual change rate of the $N D V I_{\text {res }}$ value was between -0.021 and 0.025 (Figure $5 b$ ), with an upward trend in most areas (64.27\%). This means that in most areas of Xinjiang, human activities have slightly increased the vegetation coverage.

To reflect the intensity and direction of the changing trend of anthropogenic impacts on vegetation cover more intuitively, the positive and negative directions of the average $N D V I_{\text {res }}$ values and the changing trend were superimposed, and the results were divided into five types (Figure 5c). Among them, positive impact increases (decreases) meant that the vegetation improvement (increase in NDVI) caused by anthropogenic activities showed an increasing (a decreasing) trend, while negative impact increases (decreases) meant that the vegetation degradation (decrease in NDVI) caused by anthropogenic activities showed an increasing (a decreasing) trend. From the perspectives of the proportions and spatial patterns (Figure $5 c, d$ ), the regions demonstrating positive impact increases accounted for the largest proportion (43.22\%), mainly distributed on the northern slope of the Tianshan Mountains, the oasis around the Tarim Basin, and the Altun Mountains. This type was followed by the areas with negative impact increases (23.96\%); these areas were mainly scattered in the Junggar Basin, the Turpan Basin, and the western Tianshan Mountains. The areas with a negative impact decrease accounted for $21.05 \%$ of the vegetated areas, and mainly appeared in the Ili River Valley, Tacheng, and the northern foot of the Kunlun Mountains. The distribution of the areas with positive impact decreases is relatively scattered, accounting for $11.77 \%$ of the vegetated areas. In general, the anthropogenic effects of vegetation changes in Xinjiang mainly included positive impact increases, indicating that human activities have improved the ecological environment of Xinjiang from 2000 to 2018.

Positive trends dominated the impacts of anthropogenic activities on all types of vegetation, but the changing trends of anthropogenic influences varied significantly among different vegetation types (Figure $5 \mathrm{~d}$ ). Crops have the highest proportion of positive impact increases, reaching $66.53 \%$, followed by shrubs and sparse vegetation, which accounted for $47.55 \%$ and $45.03 \%$, respectively. The highest percentage of positive impact decreases was alpine vegetation $(19.66 \%)$, followed by forests $(19.07 \%)$. The proportion of negative impact decreases was highest in grasslands $(25.63 \%)$, followed by alpine vegetation $(21.29 \%)$. The highest proportion of negative impact increases occurred in forests, followed by shrubs and alpine vegetation, which accounted for $29.34 \%, 27.97 \%$, and $24.99 \%$ of the area, respectively. 
In general, anthropogenic activities promoted the continuous increase in the NDVI of various vegetation types from 2000 to 2018, especially crops, shrubs, and sparse vegetation. However, the increases in the negative impact of human activities on vegetation also require special attention, especially for forests, shrubs, and alpine vegetation.
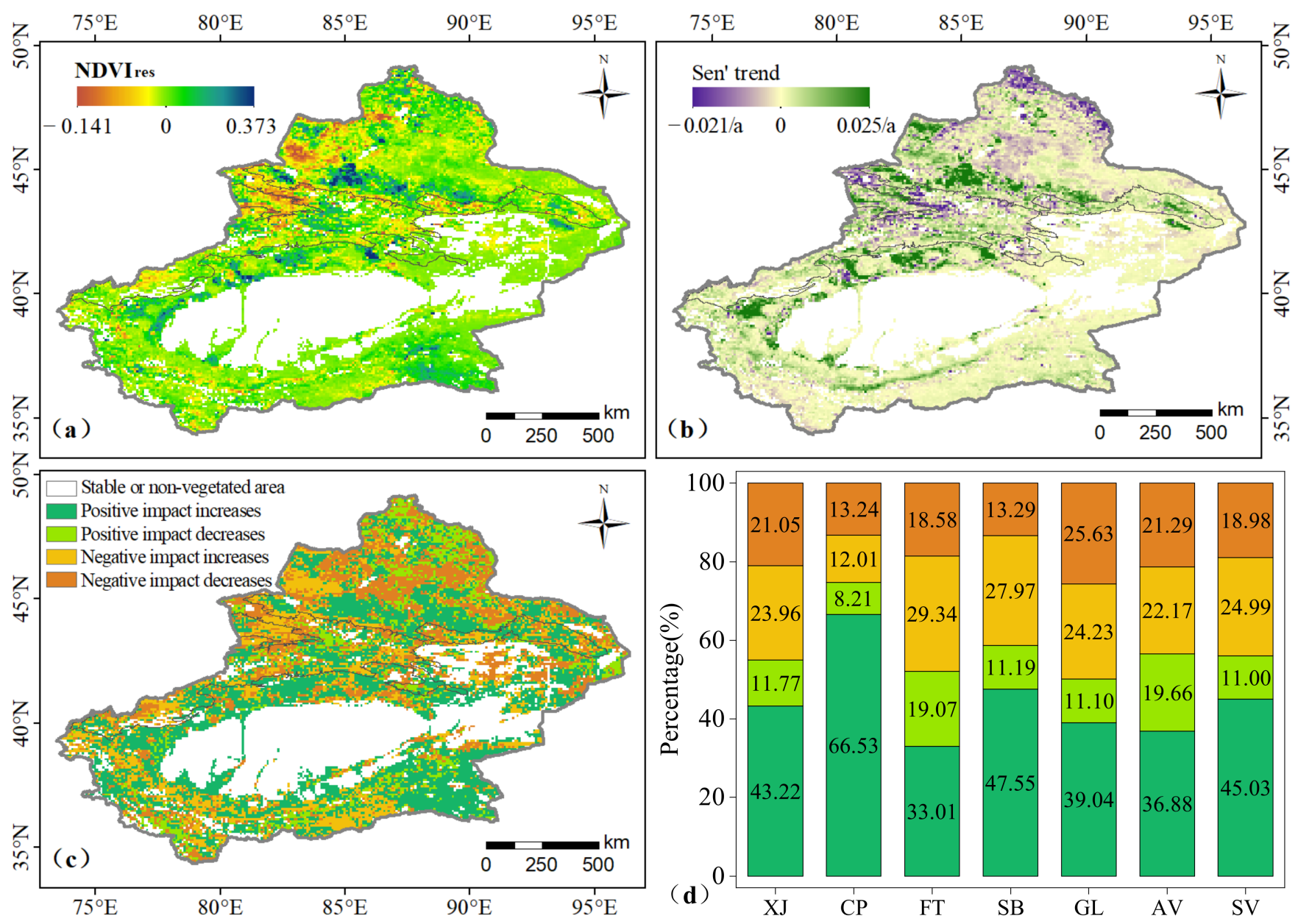

Figure 5. Change trends of $N D V I_{\text {res }}$ from 2000-2018. (a) Spatial pattern of $N D V I_{\text {res }}$; (b) annual change trends; (c) types of change trends and (d) percentage changes of different vegetation types. The legend of (d) is the same as that of (c). XJ: Xinjiang; CP: crop; FT: forest; SB: shrub; GL: grassland; AV: alpine vegetation; and SV: sparse vegetation.

From the perspective of interannual changes, $N D V I_{\text {res }}$ showed an increasing trend, with a growth rate of $0.06 \% / 10$ years (Figure 6), indicating that human activities have generally promoted the greening of vegetation in Xinjiang. Both the positive and negative impacts of human activities increased over the study period, and the growth rate of the positive influence $(0.08 \% / 10$ years) was higher than that of the negative influence $(0.04 \% / 10$ years) (Figure 6). For different types of vegetation, except for the slight decrease in the $N D V I_{\text {res }}$ of alpine vegetation, the other types of vegetation showed an increasing trend (Figure 7), especially for crops, the growth rate reached $0.28 \% / 10$ years (Figure $7 \mathrm{a}$ ). Separating the positive and negative effects, the growth rates of the positive impacts of human activities on crops, shrubs, grasslands, and sparse vegetation were greater than the negative impacts, while forests and alpine vegetation experienced the opposite impacts (Figure 7). 


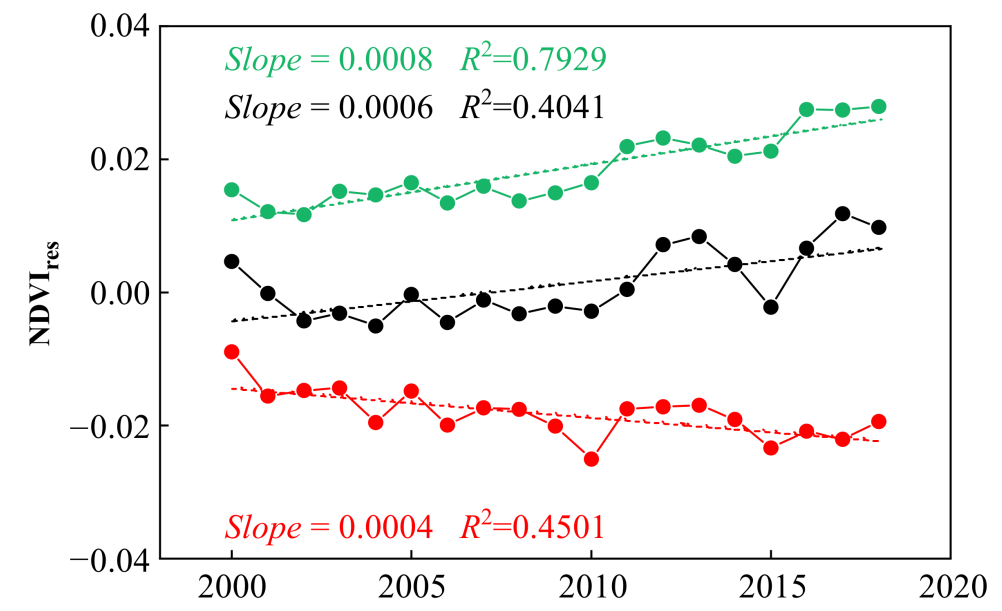

Figure 6. The interannual changes of $N D V I_{\text {res }}$ from 2000 to 2018. The black line: the average value of $N D V I_{\text {res }}$; the green line: the positive value of $N D V I_{\text {res }}$; the red line: the negative value of $N D V I_{\text {res }}$.
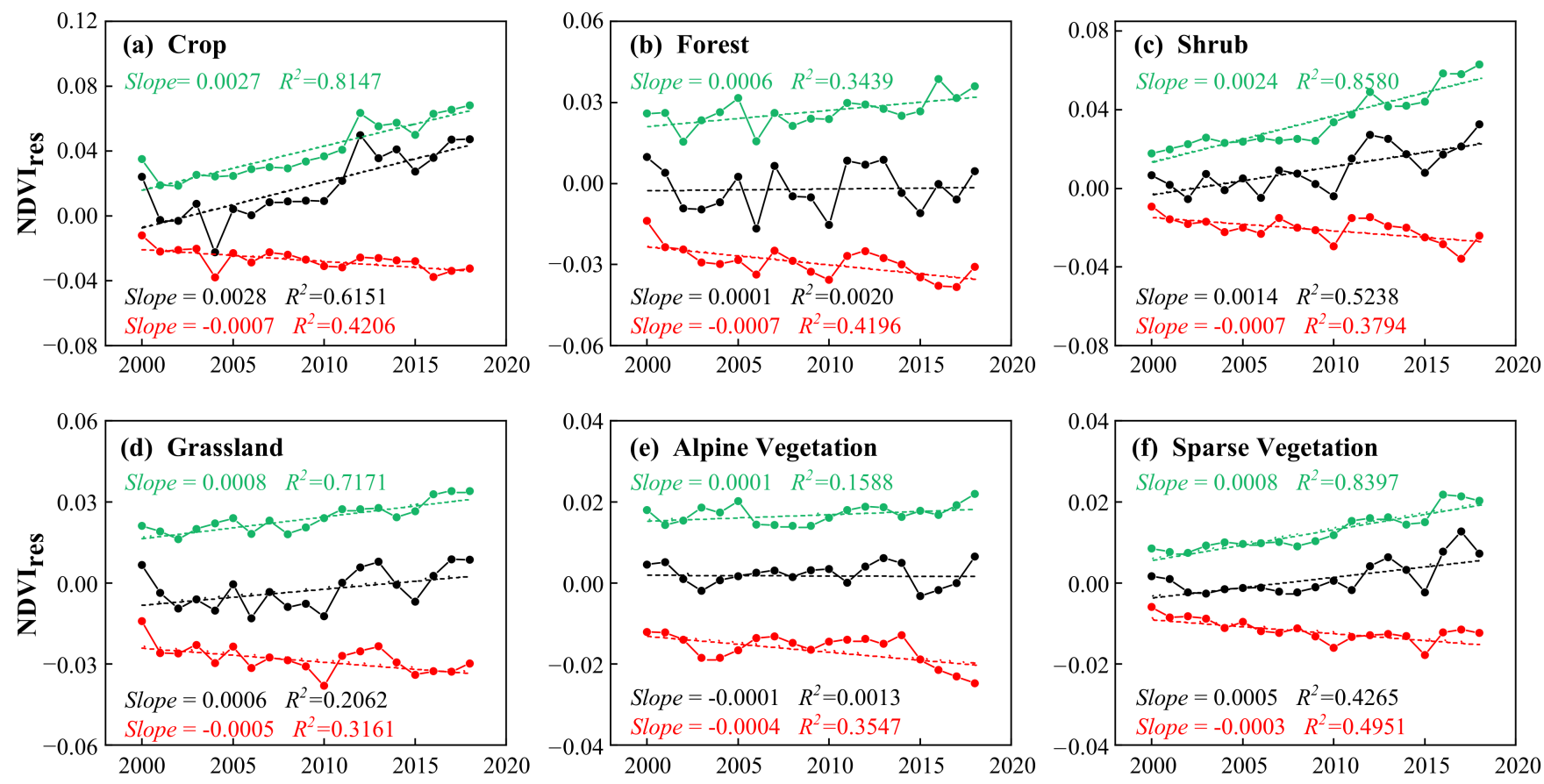

Figure 7. The interannual changes of $N D V I_{\text {res }}$ for different types of vegetation from 2000 to 2018. (a) crop; (b) forest; (c) shrub; (d) grassland; (e) alpine vegetation; (f) sparse vegetation. The black line: the average value of $N D V I_{\text {res }}$; the green line: the positive value of $N D V I_{\text {res }}$; the red line: the negative value of $N D V I_{\text {res }}$.

\subsection{Driving Analysis of Anthropogenic Impacts on Vegetation Dynamics}

As shown in Figure 8, the results of the stepwise multiple regression model of the driving factors for vegetation changes revealed the important role of human factors in vegetation growth. Due to the significant spatial differences in the social economy of Xinjiang, the relationship between vegetation and human factors varies with geographic location, showing significant spatial heterogeneity. In general, the cultivated area, GDP of primary industry, and population are the main factors causing the increase in $N D V I_{\text {res }}$, especially the cultivated area, which dominated the increase in NDVI in $30.34 \%$ of the counties (Figure 8a). The livestock number, agricultural population, and animal husbandry population are the main factors driving the reduction in $N D V I_{\text {res }}$, especially the animal husbandry population, which dominated the decrease in NDVI in $23.60 \%$ of the counties (Figure 8b). 


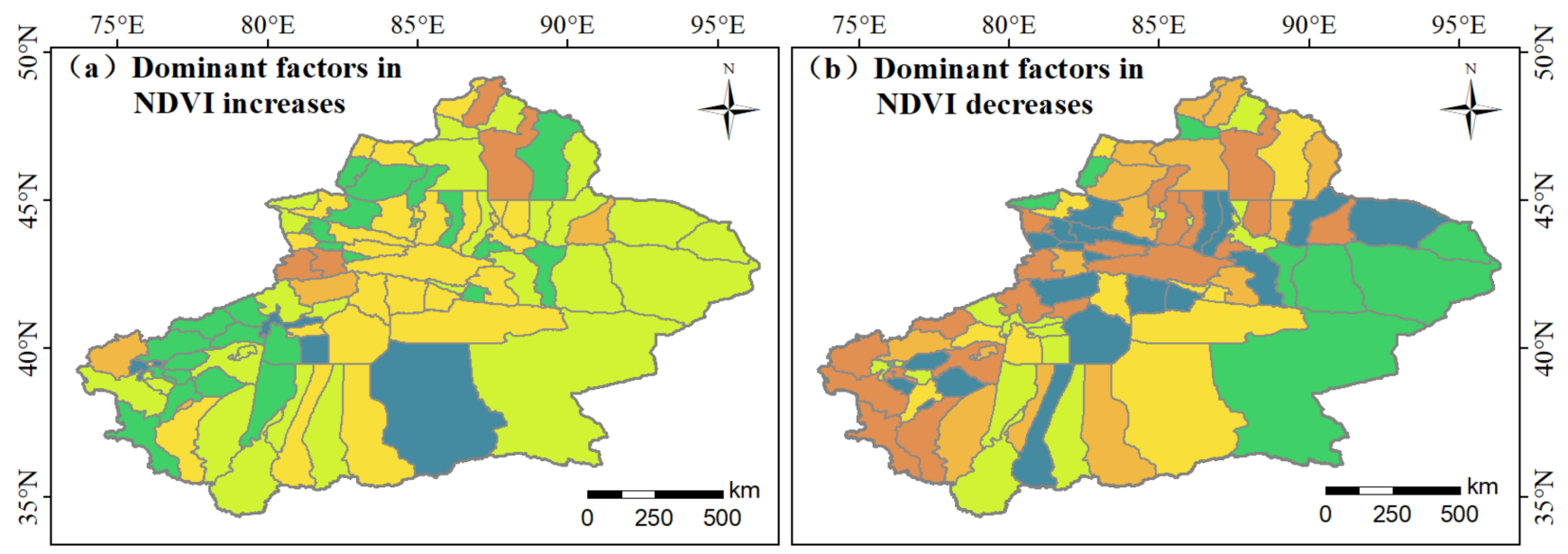

\begin{tabular}{|lcccc|}
\hline \multirow{2}{*}{ Dominant factors } & \multicolumn{2}{c}{ increases } & \multicolumn{2}{c|}{ decreases } \\
& No. of counties & Percentage & No. of counties & Percentage \\
\hline GDP of primary industry & 26 & $29.22 \%$ & 13 & $14.60 \%$ \\
\hline Population & 25 & $28.09 \%$ & 9 & $10.11 \%$ \\
\hline Agricultural population & 3 & $3.37 \%$ & 19 & $21.35 \%$ \\
\hline Animal husbandry population & 4 & $4.49 \%$ & 21 & $23.60 \%$ \\
\hline Livestock number & 4 & $4.49 \%$ & 16 & $17.98 \%$ \\
\hline Cultivated area & 27 & $30.34 \%$ & 11 & $12.36 \%$ \\
\hline
\end{tabular}

Figure 8. The anthropogenic dominant factor for the increase (a) and decrease (b) of NDVI for each county in Xinjiang.

Generally, the changes in $N D V I_{\text {res }}$ are not driven by a single force, as different anthropogenic factors dominate different parts of Xinjiang (Figure 9). For instance, the cultivated area dominated the increase in $N D V I_{\text {res }}$ in 27 counties which are located in central and southern Xinjiang, especially Wusu City and Yuli County, with a relative contribution of nearly $60 \%$ (Figures $8 \mathrm{a}$ and $9 \mathrm{e}$ ). Among the 26 counties in eastern and southern Xinjiang, the GDP of primary industry dominated the increase in NDVI res, and the relative contribution to Qinghe County and Jimunai County is the highest, reaching nearly $60 \%$ (Figures $8 \mathrm{a}$ and $9 \mathrm{a}$ ). In the 25 counties in northern and southwestern Xinjiang, the population dominated the increase in $N D V I_{\text {res }}$ (Figures $8 \mathrm{a}$ and $9 \mathrm{~b}$ ).

In the 21 counties in northern and western Xinjiang, the livestock number dominated the reduction in $N D V I_{\text {res }}$, especially in Aktao County, with a relative contribution of $85 \%$ (Figures $8 \mathbf{b}$ and $9 \mathrm{j}$ ). The agricultural population dominated the decrease in $N D V I_{\text {res }}$ in 19 counties in central and southern Xinjiang, and the relative contribution was nearly $60 \%$ in Nileke County (Figures $8 \mathrm{~b}$ and $9 \mathrm{i}$ ). The livestock number is the third-largest anthropogenic factor that caused the decrease in $N D V I_{\text {res }}$. It dominated the decrease in NDVI $I_{\text {res }}$ in 16 counties in northern and southern Xinjiang, especially in Luopu County, where the relative contribution reached $55 \%$ (Figures $8 \mathrm{~b}$ and 91 ). 


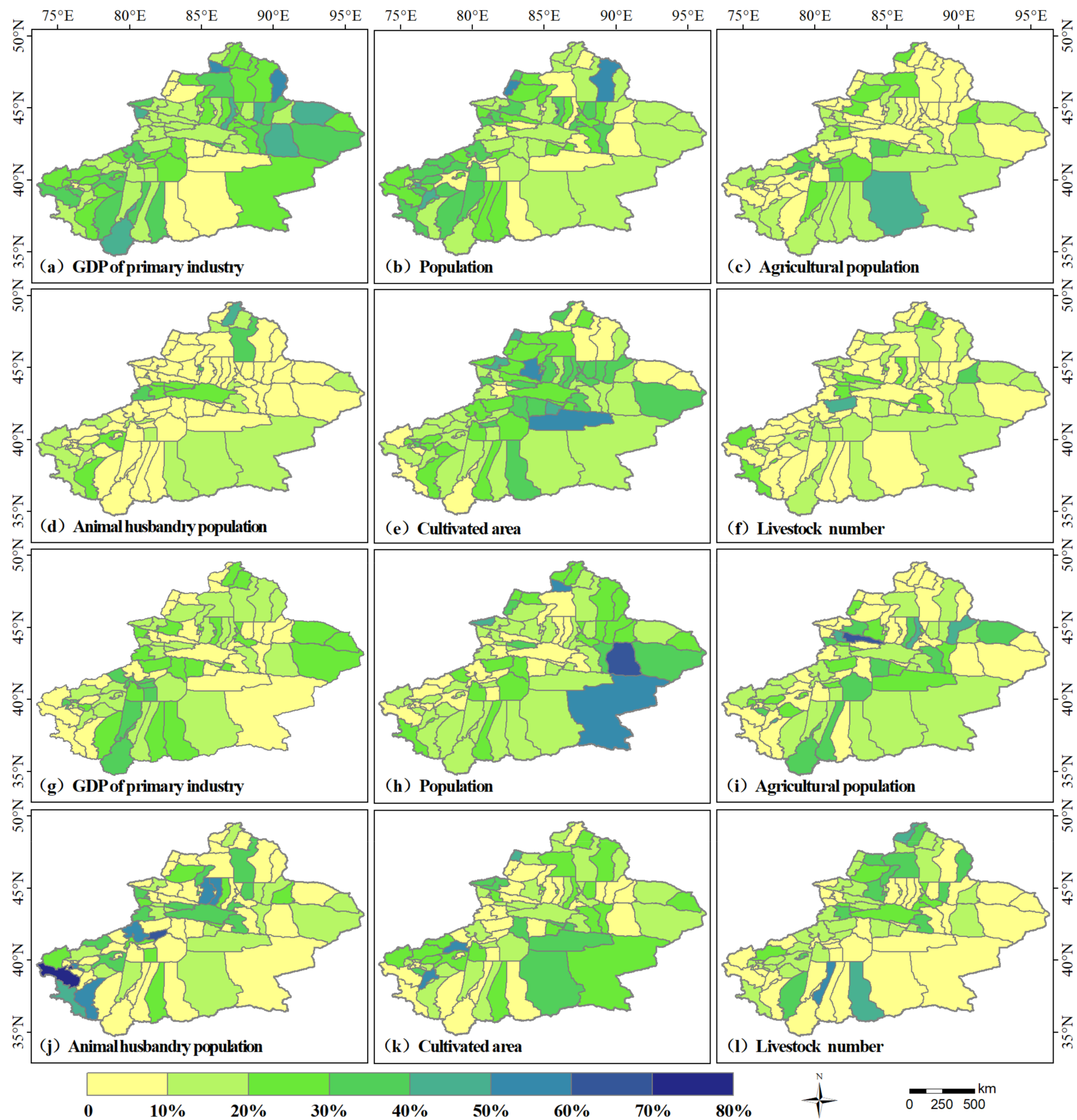

Figure 9. The relative contribution of human activities for the increase (a-f) and decrease (g-1) of NDVI for each county in Xinjiang.

\subsection{Evolution Trend of Anthropogenic Impacts on Vegetation Dynamics}

Figure 10a represents the changing pattern of the future impact of human activities on vegetation coverage based on the superimposed Hurst exponent prediction. Areas with Hurst exponent values greater than 0.5 accounted for $46.16 \%$ of the vegetated area, which indicates that the future evolution of the anthropogenic impact on vegetation coverage is consistent with the past. These areas were mainly scattered on the northern slope of the Tianshan Mountains, in the surrounding Tarim Basin, and the Altun Mountains. The Hurst exponent values below 0.5 indicate that the future evolutionary trend of the impact of human activities on vegetation coverage is opposite to the past. These areas account for 
$53.84 \%$ of the vegetated areas and are mainly distributed in the Altai Mountains, Junggar Basin, Ili River Valley, Turpan Basin, and eastern Tarim Basin. In general, the future evolutionary trend of the anthropogenic influence on vegetation cover is dominated by anti-persistence.

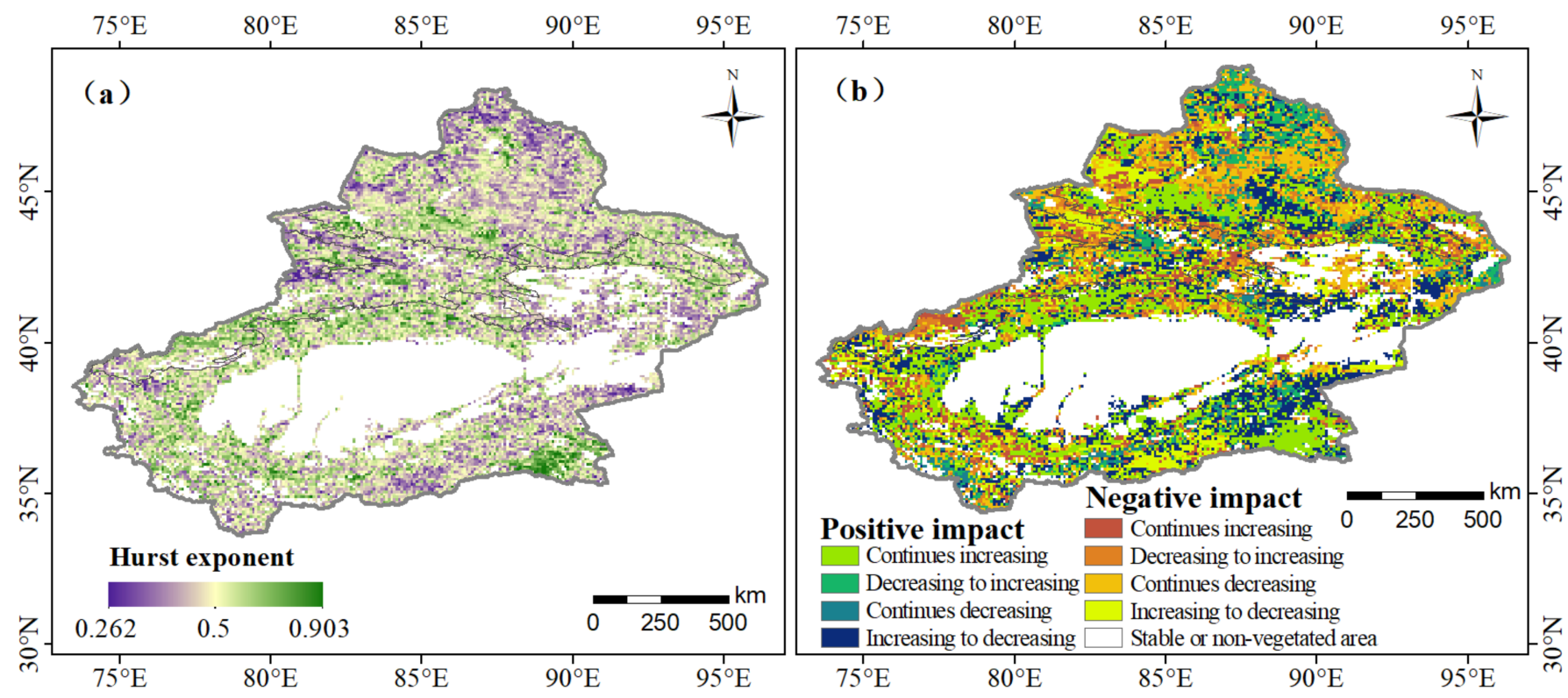

Figure 10. Spatial distributions of (a) the Hurst exponent values and (b) the evolutionary trends of anthropogenic impacts on vegetation dynamics.

To further reveal the future evolutionary trend of the anthropogenic influence on vegetation cover, we superimposed the positive and negative directions, change trend, and Hurst exponent of the $N D V I_{\text {res }}$ series and divided the results into eight types (Figure 10b). The classification results show that the persistence of the anthropogenic impact on vegetation dynamics has obvious regional characteristics. In the future, the positive impacts continuing to increase is the main feature of the impact of human activities on the vegetation changes in Xinjiang. This type of evolution accounts for about $22.56 \%$ of the vegetated area, and is mainly distributed on the northern slope of the Tianshan Mountains, the oasis in the western part of the Tarim Basin, and the Altun Mountains. Approximately $20.64 \%$ of the vegetated areas showed increasing-to-decreasing positive impacts; these regions were mainly located in the southeast of the Junggar Basin, the south of the Turpan Basin, and the southeast of the Tarim Basin. Areas with decreasing-to-increasing negative impacts were mainly scattered in the Ili Valley, the central Tianshan Mountains, and the Pamirs, accounting for $14.52 \%$ of the vegetated area. Areas with increasing-to-decreasing negative impacts accounted for $11.70 \%$ of the vegetated area, and mainly appeared in Tacheng, the Yili River Valley, and the Kunlun Mountains. The proportion of regions where negative impacts continued to decrease, negative impacts continued to increase, decreasing-to-increasing positive impacts, and positive impacts continued to decrease is relatively small, accounting for $9.44 \%, 9.36 \%, 7.02 \%$, and $4.76 \%$ of the vegetated areas, respectively. In general, the positive impact of human activities on vegetation changes in Xinjiang will continue to increase in the future.

In terms of different types of vegetation (Figure 11), areas in which positive impacts continued to increase accounted for a large proportion of crops, shrubs, grasslands, and alpine vegetation, at $44.35 \%, 32.17 \%, 19.85 \%$, and $20.91 \%$, respectively (Figure $11 \mathrm{~b}, \mathrm{~d}-\mathrm{f}$ ). Forests and sparse vegetation accounted for large proportions of increasing-to-decreasing positive impacts at $18.34 \%$ and $22.72 \%$, respectively (Figure $11 \mathrm{c}, \mathrm{g}$ ). This result indicates that the improvement effect of human activities on crops, shrubs, grasslands, and alpine 
vegetation will continue to increase, while the improvement effect on forests and sparse vegetation will gradually weaken.

(a) XJ

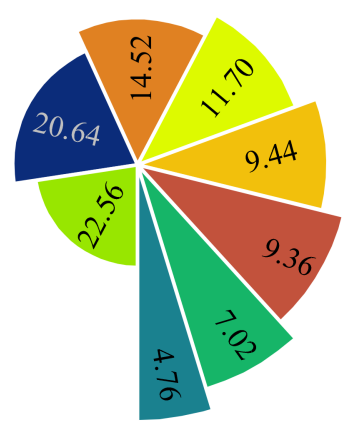

(b) Crop

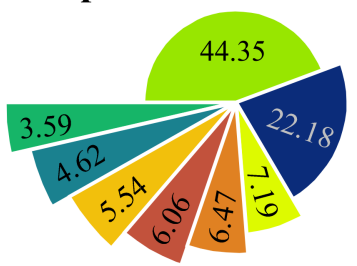

(e) Grassland

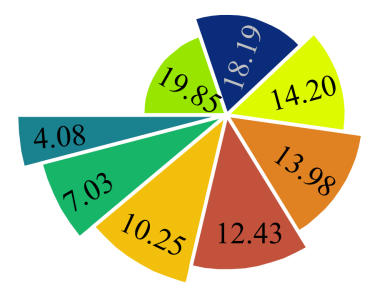

(c) Forest

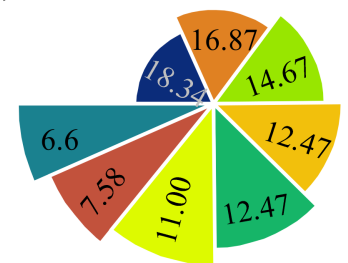

(f) Alpine vegetation

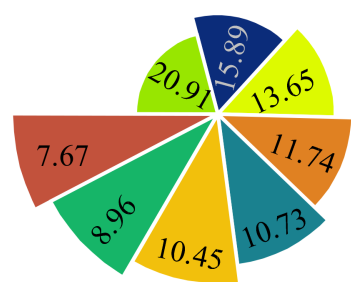

(d) Shurb

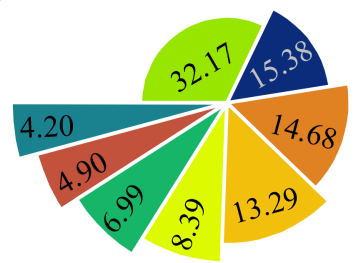

(g) Sparse vegetation

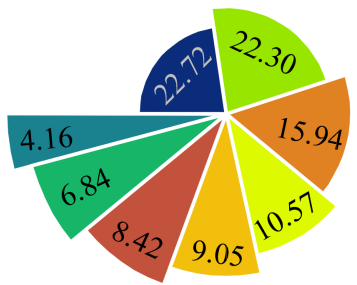

Figure 11. Percentage statistics of the evolutionary trends of anthropogenic impacts on vegetation dynamics. (a) Xinjiang; (b) crop; (c) forest; (d) shrub; (e) grassland; (f) alpine vegetation; (g) sparse vegetation. The legend is the same as that of Figure $8 b$.

\section{Discussion}

\subsection{Relationship between Anthropogenic Activities and Vegetation Changes}

In the last 37 years, the vegetation has shown a greening trend, and human activities have promoted the greening of vegetation in Xinjiang as a whole (Figures 3 and 4). In general, the cultivated area, GDP of primary industry, and population promoted the greening of vegetation, while the livestock number, agricultural population, and animal husbandry population aggravated the degradation of vegetation (Figure 8). Population dynamics have an important impact on vegetation changes [28]. On the one hand, in the process of accelerating industrialization and urbanization, surplus rural laborers are migrating to cities in search of job opportunities and higher incomes. On the other hand, the government has provided a large number of public welfare positions such as forest rangers and border guards, allowing some farmers and herdsmen to engage in non-agricultural work, especially in counties close to the border in western Xinjiang, such as Taxkorgan County, Wushi County, Atushi City, Yumin County, etc. The migration of the population from rural areas to cities and non-agricultural work have reduced human interference in the rural ecological environment and contributed to the restoration of vegetation. Furthermore, with the increase in population, a large amount of grassland and unused land has been reclaimed as cultivated land. From 2000 to 2018, the population of Xinjiang increased from 18.49 million to 24.86 million, and the area of cultivated land increased from 2.9 million hectares to 5.7 million hectares (Figure 12a). We found that a large amount of grassland and unused land on the northern slope of the Tianshan Mountains and the edge of the Tarim Basin has been reclaimed as cultivated land (Figure 13). The expansion of cultivated land has further promoted the greening of the oasis edge. In addition, the agricultural subsidies and long-term contracting rights policies implemented by government agencies [62] and the introduction of modern agricultural technology have encouraged farmers and herders to engage in agricultural activities. These measures have not only promoted the growth of the GDP of primary industry but have also promoted the development of rural greening, forming a win-win situation for farmers and the government. To alleviate the environmental problems caused by anthropogenic activities resulting from rapid economic development, China has implemented a series of large-scale ecological restoration policies, such as the TNSP, GGP, Grazing Withdrawal Program (GWP), Ecological Subsidy System 
(ESS), CCPT, and TFP, which have greatly promoted the restoration of vegetation and the natural environment $[16,18,31,63]$. It can be clearly found that a large amount of unused land around the Junggar Basin and Turpan Basin, the Kunlun Mountains, and the Altun Mountains has turned into grassland (Figure 13). Afforestation policies and intensive agriculture in China have greatly contributed to global greening [64].
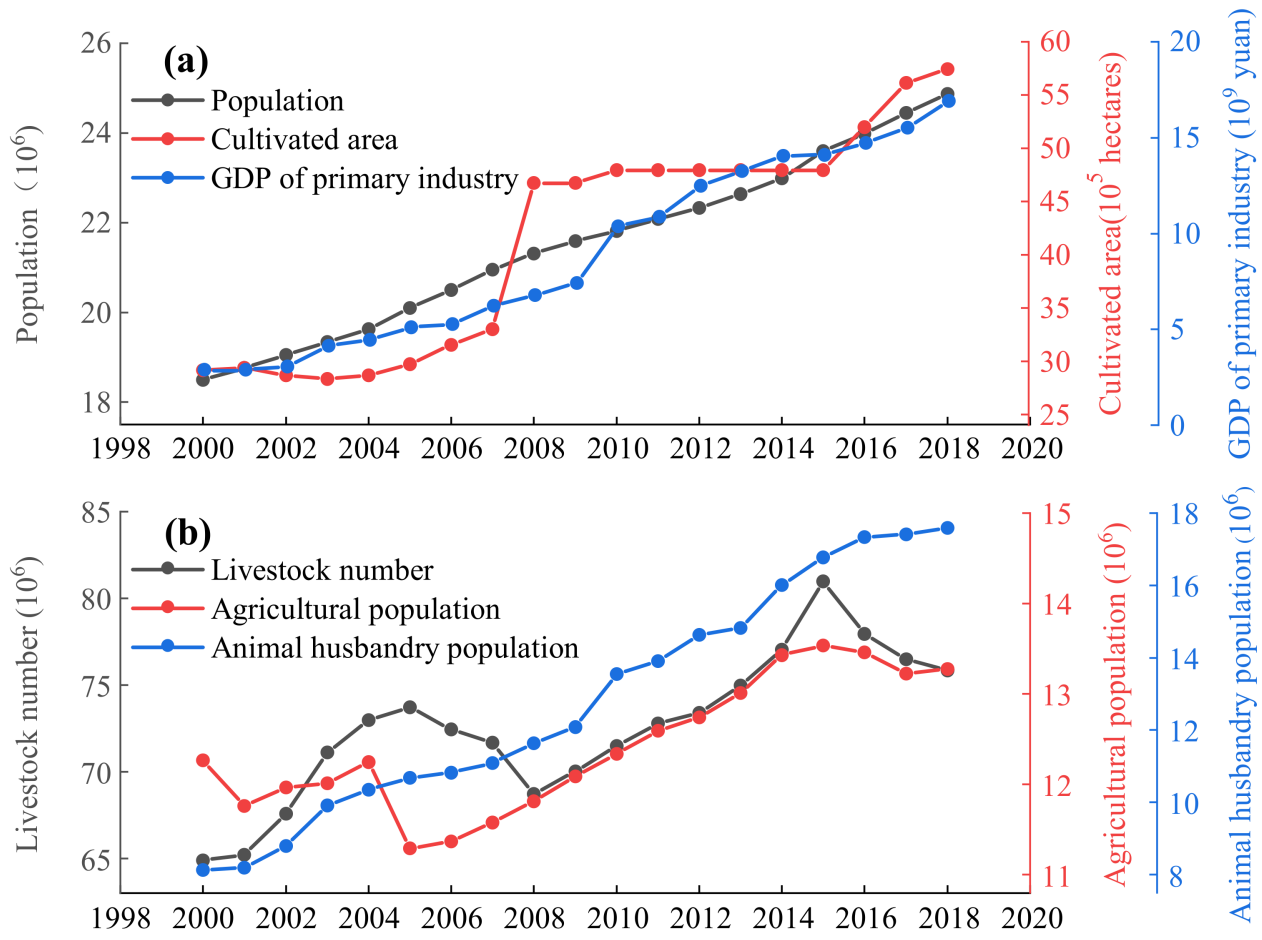

Figure 12. Change trend of human factors in Xinjiang from 2000 to 2018. (a) population, cultivated rea and GDP of primary industry; (b) livestock number, agricultural population and animal husbandry population.

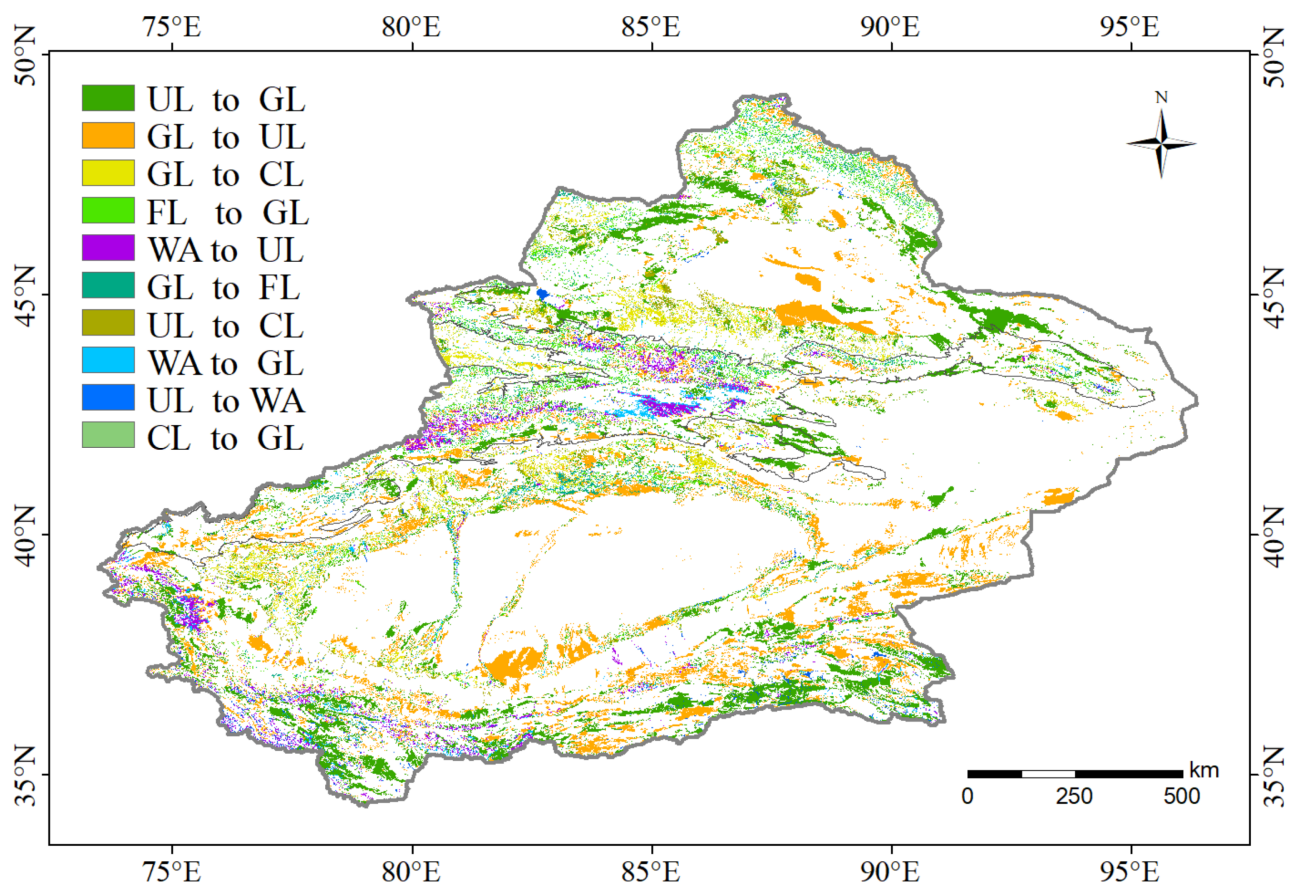

Figure 13. Major land-use changes in Xinjiang during the periods of 2000-2018. UL: unused land; GL: grassland; CL: cultivated land; FL: forest land; BL: built-up land; WA: water area. 
Although the implementation of policies such as GWP and ESS has promoted vegetation greening, the increase in livestock number, agricultural population, and animal husbandry population (Figure 12b) may disturb the ecological environment and hurt vegetation growth. For example, the phenomenon of grassland turning into unused land has been monitored in the eastern part of the Junggar Basin and southern Tarim Basin (Figure 13). The rapid development of animal husbandry and overgrazing may be the main cause of grassland degradation. Additionally, according to data from the Water Resources Department of Xinjiang Uygur Autonomous Region (http: //slt.xinjiang.gov.cn/slt/szygb/list.shtml, accessed on 5 April 2021), water consumption for agricultural production accounts for more than $95 \%$ of the total water consumption in Xinjiang, and animal husbandry has become the industry with the second-largest water consumption. The increases in cultivated areas and the livestock number lead to the consumption of large amounts of water resources, further directly or indirectly destroying the living environment of downstream forests, shrubs, and sparse vegetation. From 2000 to 2018, the water body area of Xinjiang dropped from $5.10 \times 10^{4}$ to $3.42 \times 10^{4} \mathrm{~km}^{2}$, and the areas with the greatest decrease were the central Tianshan Mountains and the Kunlun Mountains (Figure 13, Table 4). Large-scale afforestation increased evapotranspiration and reduced runoff and groundwater level, further leading to land degradation and desertification, especially in arid and semi-arid areas [38,65-67]. One study found that afforestation reduced the local groundwater level in arid regions of China by 0.5 to $3.0 \mathrm{~m}$ [68]. These negative effects offset the positive effects of human activities on vegetation to a certain extent.

Table 4. The transfer matrix of land-use changes from 2000 to 2018 (unit: $10^{4} \mathrm{~km}^{2}$ ).

\begin{tabular}{|c|c|c|c|c|c|c|c|c|c|c|}
\hline & \multirow{2}{*}{ Class } & \multicolumn{9}{|c|}{2018} \\
\hline & & GL & CL & BL & FL & WA & UL & 2018 Total & Transfer in & Change \\
\hline \multirow{8}{*}{2000} & GL & 31.59 & 2.54 & 0.15 & 1.34 & 0.51 & 11.53 & 48.1 & 16.07 & 0.44 \\
\hline & $\mathrm{CL}$ & 0.64 & 4.64 & 0.33 & 0.13 & 0.07 & 0.14 & 9.02 & 1.31 & 3.07 \\
\hline & $\mathrm{BL}$ & 0.04 & 0.2 & 0.15 & 0.01 & 0 & 0.03 & 0.87 & 0.28 & 0.44 \\
\hline & FL & 2.06 & 0.32 & 0.02 & 1.02 & 0.05 & 0.35 & 2.77 & 2.8 & -1.05 \\
\hline & WA & 0.97 & 0.11 & 0.01 & 0.05 & 1.92 & 2.04 & 3.42 & 3.18 & -1.68 \\
\hline & UL & 12.80 & 1.21 & 0.21 & 0.22 & 0.87 & 84.96 & 99.05 & 15.31 & -1.22 \\
\hline & \multirow{2}{*}{$\begin{array}{c}2000 \text { total } \\
\text { Transfer } \\
\text { out }\end{array}$} & 47.66 & 5.95 & 0.43 & 3.82 & 5.1 & 100.27 & & & \\
\hline & & 16.51 & 4.38 & 0.72 & 1.75 & 1.5 & 14.09 & & & \\
\hline
\end{tabular}

\subsection{Evolutionary Trend of Anthropogenic Impacts}

In the future, the positive impacts continuing to increase is the main feature of the impact of human activities on the vegetation changes in Xinjiang, especially in that the improvement effect of human activities on crops, shrubs, grasslands, and alpine vegetation will continue to increase. The following arguments may support this view that the positive impacts will continue to increase. First, the construction of an ecological civilization in China is aligned with the will of the country. A series of ecological restoration projects (e.g., TNSP, GGP, GWP, ESS, CCPT, and TFP) are in the process of continuous and in-depth development $[16,18,31,63]$, and the ecological benefits brought about by them will continue to increase. Second, the concept of ecological protection has been deeply rooted in the hearts of the people, and the public's awareness regarding practicing activities related to ecological protection is unprecedentedly strong. Third, the Xinjiang government vigorously promotes agricultural modernization technologies and efficient land management technologies to lay the technical foundations for greening in oasis areas and sustainable agricultural development [30]. Finally, the ecological benefits brought about by previous ecological restoration projects in Xinjiang are conducive to the sustainable development of the local ecological environment. For example, since the beginning of the 21st century, desertification control in Xinjiang has achieved remarkable results in policy mechanisms, technological models, industrial development, and management systems [69]. The reduction in desertification in Xinjiang has accelerated the increase in the vegetation greening 
rate to a large extent, and the ecosystem service functions damaged by desertification are gradually being restored [30]. Therefore, we have reason to believe that human activities can continue to promote the greening of Xinjiang's vegetation in the future.

The evolution trend of anthropogenic impacts on vegetation dynamics also shows that, in the future, the areas with increasing-to-decreasing positive impacts and decreasingto-increasing negative impacts will still account for $20.64 \%$ and $14.52 \%$ of the vegetated area, respectively. Due to the arid and semi-arid geographical environment, natural factors, especially precipitation, have a profound impact on the vegetation dynamics in Xinjiang [32,38,70]. The effectiveness of an ecological restoration project is closely related to the combined effects of natural conditions and human management [71]. To some extent, anthropogenic activities must conform to the laws of nature, and the benefits of anthropogenic activities should not be exaggerated. This may be the reason why areas in which anthropogenic positive impact increases or negative impact decreases are always highly consistent in space with areas with relatively superior natural conditions (Figures 10b and S1). In areas with restricted natural conditions, the positive impact of human activities on vegetation dynamics is limited. Thus, the over-reliance on ecological restoration projects, especially afforestation, to increase the coverage of vegetation in Xinjiang is risky. The formulation of ecological restoration policies requires the consideration of climate change and the actual geographical environment [72]. Natural restoration initiatives, such as restrictions on grazing and agriculture and the planting of droughttolerant vegetation types, may contribute to the ecological restoration of environmentally stressed areas in Xinjiang. Therefore, policymakers need to adjust their policy guidance in a timely and appropriate manner to promote the protection and sustainable development of fragile ecosystems.

\subsection{Potential Applications and Limitations}

Compared with previous models that only considered temperature and precipitation $[13,22,23]$, the average value of the determination coefficient in this study, which comprehensively considered temperature, precipitation, solar radiation, and soil moisture, increased by $45.35 \%$ (Figure S2). This study effectively improves the robustness and reliability of the NDVI values predicted based on natural factors. Through the correlation analysis of $N D V I_{o b s}$ and $N D V I_{\text {pre }}$ in areas without human impact, it is found that the correlation coefficients of the two in 2000 and 2018 reached 0.984 and 0.964 , respectively (Figure S3), indicating that the predictive regression model that we established has high accuracy. Therefore, the improved model can be applied in other areas with similar environmental backgrounds to separate the effects of natural factors and human activities on vegetation changes. Additionally, we discussed the spatiotemporal change characteristics and evolutionary trends of anthropogenic impacts on vegetation cover. This analysis is of great significance for comprehensively understanding the impact of human activities on the vegetation in Xinjiang and for further promoting the sustainable development of the ecological environment.

There are some limitations to this study. The uncertainty of the remote sensing data and meteorological data used in this study may have a certain impact on the accuracy of the evaluation results. In addition, limited to the availability of human activity data, this study mainly discussed the impact of different human activities on vegetation dynamics in Xinjiang at the county scale. However, the effects of different human activities on vegetation dynamics play different roles at different temporal and spatial scales. Therefore, it is of great practical significance to carry out quantitative research on anthropogenic driving factors at different temporal and spatial scales in future research.

\section{Conclusions}

This study improved the NDVI prediction model based on temperature, precipitation, solar radiation, and soil moisture $(0-10 \mathrm{~cm})$. By combining the residual analysis method, the anthropogenic impacts on the vegetation dynamics of Xinjiang from 1982 to 2018 were 
calculated. Based on the multiple stepwise regression model, the anthropogenic driving factors of vegetation changes were quantitatively analyzed. Trend analysis and the Hurst index method were employed to discuss the spatiotemporal characteristics and future evolutionary trends of anthropogenic influences on vegetation cover. The results reveal the following conclusions.

(1) From 1982 to 2018, the overall trend of vegetation in Xinjiang gradually improved, and the vegetation dynamics mainly significantly improved $(57.09 \%$ of the vegetated areas). The changes to all the vegetation types showed a greening trend, especially for crops.

(2) From 2000 to 2018, the anthropogenic effects of vegetation changes in Xinjiang mainly included positive impact increases. Human activities promoted the continuous increase in the NDVI of various vegetation types, especially crops, shrubs, and sparse vegetation. Both the positive and negative impacts of human activities increased over the study period, and the growth rate of the positive influence was higher than that of the negative influence.

(3) The cultivated area, GDP of primary industry, and population are the main anthropogenic factors driving the increase in vegetation NDVI, especially the cultivated area, which dominated the increase in NDVI in $30.34 \%$ of the counties. The livestock number, agricultural population, and animal husbandry population are the main anthropogenic factors driving the decrease in NDVI, especially the animal husbandry population, which dominated the decrease in NDVI in $23.60 \%$ of the counties.

(4) The evolutionary trend of the anthropogenic impact on vegetation dynamics in Xinjiang will be dominated by anti-persistence, thereby mainly showing that the positive impacts continued to increase. The evolutionary trend of anthropogenic influences on crops, shrubs, grasslands, and alpine vegetation mainly show that positive impacts will continue to increase, while forests and sparse vegetation will mainly experience increasing-to-decreasing positive impacts.

Supplementary Materials: The following are available online at https: / www.mdpi.com/article / 10.3390/rs13224651/s1. Figure S1: Spatial distribution of average annual temperature, annual precipitation, solar radiation, and soil moisture $(0-10 \mathrm{~cm})$ in Xinjiang from 1982-2018. Figure S2: Spatial distribution of determination coefficients. Figure S3: Correlation analysis of $N D V I_{o b s}$ and $N D V I_{\text {pre }}$ in areas without human impact in 2000 and 2018.

Author Contributions: Conceptualization, J.Z. and J.G.; methodology, J.Y.; software, J.G.; formal analysis, M.L.; data curation, J.Y. and M.L.; writing—original draft preparation, J.G.; writing—review and editing, J.Z.; visualization, J.G. All authors have read and agreed to the published version of the manuscript.

Funding: This research was funded by the Major Program of National Social Science Foundation of China (No. 17ZDA064), and the Tianshan Cedar Project of Xinjiang Uygur Autonomous Region (No. 2020XS04).

Institutional Review Board Statement: Not applicable.

Informed Consent Statement: Not applicable.

Data Availability Statement: The GIMMS NDVI covering the period from 1982 to 2015 were sourced from the NASA Ames Ecological Forecasting Lab (https:/ / ecocast.arc.nasa.gov/, accessed on 1 November 2019). The MODIS NDVI covering the period from 2000 to 2018 were obtained from the NASA Land Processes Distributed Active Archive Center (https:/ /lpdaac.usgs.gov/, accessed on 5 January 2020). The meteorological data were collected from the CMFD at the National Tibetan Plateau Data Center (http: / / data.tpdc.ac.cn, accessed on 15 January 2020). The soil moisture data were obtained from the GLDAS (https:/ / disc.gsfc.nasa.gov/, accessed on 15 March 2020). The DEM, vegetation type, and land use type data were obtained from the Resource and Environment Data Cloud Platform (http:/ /www.resdc.cn/, accessed on 10 April 2020).

Acknowledgments: The authors are particularly grateful to Changjiang Liu, Xiangyu Ge, and Lifang Zhang from Xinjiang University for their suggestions for improving this article. The authors would 
like to thank the editor and anonymous reviewers for their valuable comments and suggestions on this article.

Conflicts of Interest: The authors declare no conflict of interest.

\section{References}

1. Franklin, J.; Serra-Diaz, J.M.; Syphard, A.D.; Regan, H.M. Global change and terrestrial plant community dynamics. Proc. Natl. Acad. Sci. USA 2016, 113, 3725-3734. [CrossRef] [PubMed]

2. Fu, B.; Wang, S.; Liu, Y.; Liu, J.; Liang, W.; Miao, C. Hydrogeomorphic Ecosystem Responses to Natural and Anthropogenic Changes in the Loess Plateau of China. Annu. Rev. Earth Planet Sci. 2017, 45, 223-243. [CrossRef]

3. Gelfand, I.; Zenone, T.; Jasrotia, P.; Chen, J.; Hamilton, S.K.; Robertson, G.P. Carbon debt of Conservation Reserve Program (CRP) grasslands converted to bioenergy production. Proc. Natl. Acad. Sci. USA 2011, 108, 13864-13869. [CrossRef] [PubMed]

4. Liu, S.; Huang, S.; Xie, Y.; Wang, H.; Huang, Q.; Leng, G.; Li, P.; Wang, L. Spatial-temporal changes in vegetation cover in a typical semi-humid and semi-arid region in China: Changing patterns, causes and implications. Ecol. Indic. 2019, 98, 462-475. [CrossRef]

5. Peng, J.; Liu, Z.; Liu, Y.; Wu, J.; Han, Y. Trend analysis of vegetation dynamics in Qinghai-Tibet Plateau using Hurst Exponent. Ecol. Indic. 2012, 14, 28-39. [CrossRef]

6. Piao, S.; Wang, X.; Ciais, P.; Zhu, B.; Wang, T.; Liu, J. Changes in satellite-derived vegetation growth trend in temperate and boreal Eurasia from 1982 to 2006. Glob. Chang. Biol. 2011, 17, 3228-3239. [CrossRef]

7. Lioubimtseva, E. A multi-scale assessment of human vulnerability to climate change in the Aral Sea basin. Environ. Earth Sci. 2015, 73, 719-729. [CrossRef]

8. Wen, Z.; Wu, S.; Chen, J.; Lü, M. NDVI indicated long-term interannual changes in vegetation activities and their responses to climatic and anthropogenic factors in the Three Gorges Reservoir Region, China. Sci. Total Environ. 2017, 574, 947-959. [CrossRef] [PubMed]

9. Richardson, A.D.; Keenan, T.F.; Migliavacca, M.; Ryu, Y.; Sonnentag, O.; Toomey, M. Climate change, phenology, and phenological control of vegetation feedbacks to the climate system. Agric. For. Meteorol. 2013, 169, 156-173. [CrossRef]

10. Du, J.; Quan, Z.; Fang, S.; Liu, C.; Wu, J.; Fu, Q. Spatiotemporal changes in vegetation coverage and its causes in China since the Chinese economic reform. Environ. Sci. Pollut. Res. 2020, 27, 1144-1159. [CrossRef]

11. Niu, Q.; Xiao, X.; Zhang, Y.; Qin, Y.; Dang, X.; Wang, J.; Zou, Z.; Doughty, R.B.; Brandt, M.; Tong, X.; et al. Ecological engineering projects increased vegetation cover, production, and biomass in semiarid and subhumid Northern China. Land Degrad. Dev. 2019, 30, 1620-1631. [CrossRef]

12. Chen, H.; Shao, L.; Zhao, M.; Zhang, X.; Zhang, D. Grassland conservation programs, vegetation rehabilitation and spatial dependency in Inner Mongolia, China. Land Use Policy 2017, 64, 429-439. [CrossRef]

13. Qi, X.; Jia, J.; Liu, H.; Lin, Z. Relative importance of climate change and human activities for vegetation changes on China's silk road economic belt over multiple timescales. Catena 2019, 180, 224-237. [CrossRef]

14. Li, J.; Peng, S.; Li, Z. Detecting and attributing vegetation changes on China's Loess Plateau. Agric. For. Meteorol. 2017, 247, 260-270. [CrossRef]

15. Liu, Z.; Liu, Y.; Li, Y. Anthropogenic contributions dominate trends of vegetation cover change over the farming-pastoral ecotone of northern China. Ecol. Indic. 2018, 95, 370-378. [CrossRef]

16. Bryan, B.A.; Gao, L.; Ye, Y.; Sun, X.; Connor, J.D.; Crossman, N.D.; Stafford-Smith, M.; Wu, J.; He, C.; Yu, D.; et al. China's response to a national land-system sustainability emergency. Nature 2018, 559, 193-204. [CrossRef] [PubMed]

17. Lamchin, M.; Lee, W.-K.; Jeon, S.W.; Wang, S.W.; Lim, C.H.; Song, C.; Sung, M. Long-term trend and correlation between vegetation greenness and climate variables in Asia based on satellite data. Sci. Total Environ. 2018, 618, 1089-1095. [CrossRef]

18. Wu, Z.; Yu, L.; Zhang, X.; Du, Z.; Zhang, H. Satellite-based large-scale vegetation dynamics in ecological restoration programmes of Northern China. Int. J. Remote Sens. 2019, 40, 2296-2312. [CrossRef]

19. Ma, B.; Wang, S.; Mupenzi, C.; Li, H.; Ma, J.; Li, Z. Quantitative Contributions of Climate Change and Human Activities to Vegetation Changes in the Upper White Nile River. Remote Sens. 2021, 13, 3648. [CrossRef]

20. Liu, X.; Xin, L. China's deserts greening and response to climate variability and human activities. PLoS ONE 2021, 16, e0256462. [CrossRef]

21. Evans, J.; Geerken, R. Discrimination between climate and human-induced dryland degradation. J. Arid Environ. 2004, 57, 535-554. [CrossRef]

22. Li, Y.; Xie, Z.; Qin, Y.; Zheng, Z. Estimating Relations of Vegetation, Climate Change, and Human Activity: A Case Study in the $400 \mathrm{~mm}$ Annual Precipitation Fluctuation Zone, China. Remote Sens. 2019, 11, 1159. [CrossRef]

23. Jiang, L.; Guli.Jiapaer; Bao, A.; Guo, H.; Ndayisaba, F. Vegetation dynamics and responses to climate change and human activities in Central Asia. Sci. Total Environ. 2017, 599-600, 967-980. [CrossRef] [PubMed]

24. Yang, L.; Wei, W.; Wang, T.; Li, L. Temporal-spatial variations of vegetation cover and surface soil moisture in the growing season across the mountain-oasis-desert system in Xinjiang, China. Geocarto Int. 2021, 0, 1-29. [CrossRef]

25. Liu, L.; Gudmundsson, L.; Hauser, M.; Qin, D.; Li, S.; Seneviratne, S.I. Soil moisture dominates dryness stress on ecosystem production globally. Nat. Commun. 2020, 11, 4892. [CrossRef] [PubMed]

26. Granger, J.E.; Schulze, R.E. Incoming solar radiation patterns and vegetation response: Examples from the natal drakensberg. Vegetatio 1977, 35, 47-54. [CrossRef] 
27. Guo, E.; Wang, Y.; Wang, C.; Sun, Z.; Bao, Y.; Mandula, N.; Jirigala, B.; Bao, Y.; Li, H. NDVI Indicates Long-Term Dynamics of Vegetation and Its Driving Forces from Climatic and Anthropogenic Factors in Mongolian Plateau. Remote Sens. 2021, 13, 688. [CrossRef]

28. Naeem, S.; Zhang, Y.; Zhang, X.; Tian, J.; Abbas, S.; Luo, L.; Meresa, H.K. Both climate and socioeconomic drivers contribute to vegetation greening of the Loess Plateau. Sci. Bull. 2021, 66, 1160-1163. [CrossRef]

29. Hu, M.; Xia, B. A significant increase in the normalized difference vegetation index during the rapid economic development in the Pearl River Delta of China. Land Degrad. Dev. 2018, 30, 359-370. [CrossRef]

30. He, P.; Sun, Z.; Han, Z.; Dong, Y.; Liu, H.; Meng, X.; Ma, J. Dynamic characteristics and driving factors of vegetation greenness under changing environments in Xinjiang, China. Environ. Sci. Pollut. Res. 2021, 28, 42516-42532. [CrossRef] [PubMed]

31. Jiang, Y.; Guo, J.; Peng, Q.; Guan, Y.; Zhang, Y.; Zhang, R. The effects of climate factors and human activities on net primary productivity in Xinjiang. Int. J. Biometeorol. 2020, 64, 765-777. [CrossRef]

32. Jiapaer, G.; Liang, S.; Yi, Q.; Liu, J. Vegetation dynamics and responses to recent climate change in Xinjiang using leaf area index as an indicator. Ecol. Indic. 2015, 58, 64-76. [CrossRef]

33. Yao, J.; Hu, W.; Chen, Y.; Huo, W.; Zhao, Y.; Mao, W.; Yang, Q. Hydro-climatic changes and their impacts on vegetation in Xinjiang, Central Asia. Sci. Total Environ. 2019, 660, 724-732. [CrossRef] [PubMed]

34. Chen, Y.; Li, Z.; Fan, Y.; Wang, H.; Deng, H. Progress and prospects of climate change impacts on hydrology in the arid region of northwest China. Environ. Res. 2015, 139, 11-19. [CrossRef] [PubMed]

35. Shi, Y.; Shen, Y.; Kang, E.; Li, D.; Ding, Y.; Zhang, G.; Hu, R. Recent and future climate change in northwest China. Clim. Chang. 2007, 80, 379-393. [CrossRef]

36. Jiang, Y.; Wang, R.; Peng, Q.; Wu, X.; Ning, H.; Li, C. The relationship between drought activity and vegetation cover in Northwest China from 1982 to 2013. Nat. Hazards 2018, 92, 145-163. [CrossRef]

37. Jia, K.; Liang, S.L.; Liu, J.Y.; Li, Q.Z.; Wei, X.Q.; Yuan, W.P.; Yao, Y.J. Forest cover changes in the Three-North Shelter Forest Region of China during 1990 to 2005. J. Environ. Inform. 2015, 26, 112-120. [CrossRef]

38. Deng, C.; Zhang, B.; Cheng, L.; Hu, L.; Chen, F. Vegetation dynamics and their effects on surface water-energy balance over the Three-North Region of China. Agric. For. Meteorol. 2019, 275, 79-90. [CrossRef]

39. Chen, F.H.; Huang, W. Multi-scale climate variations in the arid Central Asia. Adv. Clim. Chang. Res. 2017, 8, 1-2. [CrossRef]

40. Yang, H.; Mu, S.; Li, J. Effects of ecological restoration projects on land use and land cover change and its influences on territorial NPP in Xinjiang, China. Catena 2014, 115, 85-95. [CrossRef]

41. Holben, B.N. Characteristics of maximum-value composite images from temporal AVHRR data. Int. J. Remote Sens. 1986, 7, 1417-1434. [CrossRef]

42. Li, Z.; Chen, Y.; Li, W.; Deng, H.; Fang, G. Potential impacts of climate change on vegetation dynamics in Central Asia. J. Geophys. Res. 2015, 120, 12345-12356. [CrossRef]

43. Xu, Y.; Yang, J.; Chen, Y. NDVI-based vegetation responses to climate change in an arid area of China. Theor. Appl. Climatol. 2016, 126, 213-222. [CrossRef]

44. Environmental Systems Research Institute. Resample. Available online: https://desktop.arcgis.com/en/arcmap/latest/tools/ data-management-toolbox/resample.htm (accessed on 20 October 2021).

45. He, J.; Yang, K.; Tang, W.; Lu, H.; Qin, J.; Chen, Y.; Li, X. The first high-resolution meteorological forcing dataset for land process studies over China. Sci. Data 2020, 7, 25. [CrossRef] [PubMed]

46. Yang, K.; He, J.; Tang, W.; Qin, J.; Cheng, C.C.K. On downward shortwave and longwave radiations over high altitude regions: Observation and modeling in the Tibetan Plateau. Agric. For. Meteorol. 2010, 150, 38-46. [CrossRef]

47. Chen, Y.; Yang, K.; He, J.; Qin, J.; Shi, J.; Du, J.; He, Q. Improving land surface temperature modeling for dry land of China. J. Geophys. Res. 2011, 116, D20104. [CrossRef]

48. Chen, Y.; Yang, K.; Qin, J.; Zhao, L.; Tang, W.; Han, M. Evaluation of AMSR-E retrievals and GLDAS simulations against observations of a soil moisture network on the central Tibetan Plateau. J. Geophys. Res. Atmos. 2013, 118, 4466-4475. [CrossRef]

49. Gu, X.; Li, J.; Chen, Y.D.; Kong, D.; Liu, J. Consistency and Discrepancy of Global Surface Soil Moisture Changes From Multiple Model-Based Data Sets Against Satellite Observations. J. Geophys. Res. Atmos. 2019, 124, 1474-1495. [CrossRef]

50. Wang, J.; Li, X.; Christakos, G.; Liao, Y.; Zhang, T.; Gu, X.; Zheng, X. Geographical Detectors-Based Health Risk Assessment and its Application in the Neural Tube Defects Study of the Heshun Region, China. Int. J. Geogr. Inf. Sci. 2010, 24, 107-127. [CrossRef]

51. Wang, J.; Zhang, T.; Fu, B. A measure of spatial stratified heterogeneity. Ecol. Indic. 2016, 67, 250-256. [CrossRef]

52. Peng, W.; Kuang, T.; Tao, S. Quantifying influences of natural factors on vegetation NDVI changes based on geographical detector in Sichuan, western China. J. Clean. Prod. 2019, 233, 353-367. [CrossRef]

53. Zhang, Y.; Liang, W.; Liao, Z.; Han, Z.; Xu, X.; Jiao, R.; Liu, H. Effects of climate change on lake area and vegetation cover over the past 55 years in Northeast Inner Mongolia grassland, China. Theor. Appl. Climatol. 2019, 138, 13-25. [CrossRef]

54. Liu, Y.; Li, J. Geographic detection and optimizing decision of the differentiation mechanism of rural poverty in China. Acta Geogr. Sin. 2017, 72, 161-173. [CrossRef]

55. Sen, P.K. Estimates of the Regression Coefficient Based on Kendall's Tau. J. Am. Stat. Assoc. 1968, 63, 1379-1389. [CrossRef]

56. Mann, H.B. Non-Parametric Test Against Trend. Econometrica 1945, 13, 245-259. [CrossRef]

57. Kendall, M.G. Rank Correlation Methods, 4th ed.; Charles Grifin: London, UK, 1975. 
58. Gocic, M.; Trajkovic, S. Analysis of changes in meteorological variables using Mann-Kendall and Sen's slope estimator statistical tests in Serbia. Glob. Planet. Chang. 2013, 100, 172-182. [CrossRef]

59. Grömping, U. Relative importance for linear regression in R: The package relaimpo. J. Stat. Softw. 2006, 17, 1-27. [CrossRef]

60. Yao, Y.; Wang, X.; Li, Y.; Wang, T.; Shen, M.; Du, M.; He, H.; Li, Y.; Luo, W.; Ma, M.; et al. Spatiotemporal pattern of gross primary productivity and its covariation with climate in China over the last thirty years. Glob. Chang. Biol. 2018, 24, 184-196. [CrossRef] [PubMed]

61. Hurst, H.E. Long-term Storage Capacity of Reservoirs. Trans. Am. Soc. Civ. Eng. 1951, 116, 770-799. [CrossRef]

62. Vendryes, T. Land Rights in Rural China since 1978. China Perspect. 2010, 2010. [CrossRef]

63. Zhou, Z.; Ding, Y.; Shi, H.; Cai, H.; Fu, Q.; Liu, S.; Li, T. Analysis and prediction of vegetation dynamic changes in China: Past, present and future. Ecol. Indic. 2020, 117, 106642. [CrossRef]

64. Chen, C.; Park, T.; Wang, X.; Piao, S.; Xu, B.; Chaturvedi, R.K.; Fuchs, R.; Brovkin, V.; Ciais, P.; Fensholt, R.; et al. China and India lead in greening of the world through land-use management. Nat. Sustain. 2019, 2, 122-129. [CrossRef] [PubMed]

65. An, W.; Li, Z.; Wang, S.; Wu, X.; Lu, Y.; Liu, G.; Fu, B. Exploring the effects of the "Grain for Green" program on the differences in soil water in the semi-arid Loess Plateau of China. Ecol. Eng. 2017, 107, 144-151. [CrossRef]

66. Cao, S.; Zhang, J.; Chen, L.; Zhao, T. Ecosystem water imbalances created during ecological restoration by afforestation in China, and lessons for other developing countries. J. Environ. Manag. 2016, 183, 843-849. [CrossRef] [PubMed]

67. Cao, S.; Chen, L.; Shankman, D.; Wang, C.; Wang, X.; Zhang, H. Excessive reliance on afforestation in China's arid and semi-arid regions: Lessons in ecological restoration. Earth-Sci. Rev. 2011, 104, 240-245. [CrossRef]

68. Lu, C.; Zhao, T.; Shi, X.; Cao, S. Ecological restoration by afforestation may increase groundwater depth and create potentially large ecological and water opportunity costs in arid and semiarid China. J. Clean. Prod. 2018, 176, 1213-1222. [CrossRef]

69. Lyu, Y.; Shi, P.; Han, G.; Liu, L.; Guo, L.; Hu, X.; Zhang, G. Desertification Control Practices in China. Sustainability 2020, $12,3258$. [CrossRef]

70. Duan, H.; Yan, C.; Tsunekawa, A.; Song, X.; Li, S.; Xie, J. Assessing vegetation dynamics in the Three-North Shelter Forest region of China using AVHRR NDVI data. Environ. Earth Sci. 2011, 64, 1011-1020. [CrossRef]

71. Tong, S.; Zhang, J.; Bao, Y.; Wurina; Terigele; Weilisi. Lianxiao Spatial and temporal variations of vegetation cover and the relationships with climate factors in Inner Mongolia based on GIMMS NDVI3g data. J. Arid Land 2017, 9, 394-407. [CrossRef]

72. Qu, S.; Wang, L.; Lin, A.; Yu, D.; Yuan, M.; Li, C. Distinguishing the impacts of climate change and anthropogenic factors on vegetation dynamics in the Yangtze River Basin, China. Ecol. Indic. 2020, 108, 105724. [CrossRef] 